\title{
Impact of the 2009 major sudden stratospheric warming on the composition of the stratosphere
}

\author{
M. Tao ${ }^{1}$, P. Konopka ${ }^{1}$, F. Ploeger ${ }^{1}$, J.-U. Grooß ${ }^{1}$, R. Müller ${ }^{1}$, C. M. Volk ${ }^{2}$, K. A. Walker ${ }^{3}$, and M. Riese ${ }^{1}$ \\ ${ }^{1}$ Forschungszentrum Jülich (IEK-7: Stratosphere), Jülich, Germany \\ ${ }^{2}$ Department of Physics, University of Wuppertal, Wuppertal, Germany \\ ${ }^{3}$ Department of Physics, University of Toronto, Toronto, Ontario, Canada \\ Correspondence to: M. Tao (m.tao@fz-juelich.de)
}

Received: 11 December 2014 - Published in Atmos. Chem. Phys. Discuss.: 17 February 2015

Revised: 24 July 2015 - Accepted: 28 July 2015 - Published: 7 August 2015

\begin{abstract}
In a case study of a remarkable major sudden stratospheric warming (SSW) during the boreal winter 2008/09, we investigate how transport and mixing triggered by this event affected the composition of the entire stratosphere in the Northern Hemisphere. We simulate this event with the Chemical Lagrangian Model of the Stratosphere (CLaMS), both with optimized mixing parameters and with no mixing, i.e. with transport occurring only along the Lagrangian trajectories. The results are investigated by using tracer-tracer correlations and by applying the transformed Eulerian-mean formalism. The CLaMS simulation of $\mathrm{N}_{2} \mathrm{O}$ and $\mathrm{O}_{3}$, and in particular of the $\mathrm{O}_{3}-\mathrm{N}_{2} \mathrm{O}$ tracer correlations with optimized mixing parameters, shows good agreement with the Aura Microwave Limb Sounder (MLS) data. The spatial distribution of mixing intensity in CLaMS correlates fairly well with the Eliassen-Palm flux convergence. This correlation illustrates how planetary waves drive mixing. By comparing simulations with and without mixing, we find that after the SSW, poleward transport of air increases, not only across the vortex edge but also across the subtropical transport barrier. Moreover, the SSW event, at the same time, accelerates polar descent and tropical ascent of the BrewerDobson circulation. The accelerated ascent in the tropics and descent at high latitudes first occurs in the upper stratosphere and then propagates downward to the lower stratosphere. This downward propagation takes over 1 month from the potential temperature level of 1000 to $400 \mathrm{~K}$.
\end{abstract}

\section{Introduction}

A major sudden stratospheric warming (major SSW) is a dramatic phenomenon with strong wind disturbance and polar temperature rise in the winter stratosphere, associated with transport of air from low to high latitudes (see e.g. Andrews et al., 1987). The mechanism of SSWs has been understood as a result of tropospheric waves propagating upwards into the stratosphere and breaking at a certain level (Matsuno, 1971). Planetary-scale waves can be diagnosed by the Eliassen-Palm (EP) flux and its divergence (e.g. Eliassen, 1951; Plumb and Bell, 1982). In particular, positive and negative values of the EP flux divergence quantify the acceleration and deceleration of the westerly zonal flow, respectively, driving the Brewer-Dobson (BD) circulation (e.g. Holton et al., 1995).

Resolving filamentary structures explicitly and realistically, representing the dissipation/mixing processes in models, is important for simulating non-linear chemical reactions accurately (Tuck, 1986; Orsolini et al., 1997; Edouard et al., 1996; Konopka et al., 2003). However, resolving these structures accurately is a general difficulty for chemical transport models (e.g. Sutton et al., 1994; Fairlie et al., 1997; Manney et al., 1998). During a SSW event, strong large-scale planetary waves propagate, break and finally dissipate - a process that occurs almost isentropically, i.e. on levels with a constant potential temperature. In the stratospheric chemical tracer fields, the SSW itself is characterized by the existence of filamentary structures on a broad range of spatial scales (see e.g. McIntyre and Palmer, 1983; Konopka et al., 2003, 2005; Grooß et al., 2005b). Therefore, quantitative under- 
standing of SSWs is a challenge for current chemical transport models in particular in terms of coupling between dynamics, transport and chemistry.

To improve the understanding of SSWs, many case studies based on reanalysis data, modelling and/or satellite data have been performed. Manney et al. $(2005,2008)$ described the synoptic evolution during the 2004 and 2006 sudden stratospheric warmings (SSW). Based on the Aura Microwave Limb Sounder (MLS) observations, the meteorology and trace gases from the UTLS (upper troposphere and lower stratosphere) to the lower mesosphere during the 2006 and 2009 SSWs were extensively studied (Manney et al., 2009a, b). Using satellite temperature measurements during three major SSWs, an anomalously strong descent of mesospheric air into the upper stratosphere was found, along with the stratopause breaking down and then reforming above $75 \mathrm{~km}$ (Manney et al., 2008, 2009b; Randall et al., 2009; Orsolini et al., 2010). The major SSW in 2009 was the most intensive and prolonged case on record (Manney et al., 2009b) and this event happened although typical known external factors, e.g. the quasi-biennial oscillation, the Southern Oscillation and the 11-year sunspot cycle, were all unfavourable for the occurrence of a SSW (Labitzke and Kunze, 2009). Ayarzagüena et al. (2011) and Harada et al. (2010) studied this event from the perspective of tropospheric forcing. Both studies pointed out that the pronounced planetary wave- 2 in the stratosphere, which triggered the 2009 SSW, is associated with a highpressure ridge over the Pacific.

The remarkable stratospheric warming event in 2009 strongly influenced the distribution of chemical species. The amount of air transported out of the polar vortex into the mid latitudes in the mid stratosphere was weak until 1 week before the onset of the major SSW and became strong with a weak vortex transport barrier within a month after SSW onset until the reestablishment of a vortex barrier (Manney et al., 2009b). Kuttippurath and Nikulin (2012) diagnosed an increasing trend of occurrence of NH (Northern Hemisphere) major SSWs in recent years (1999-2011). They confirmed a weakening in the chlorine-induced ozone loss after the onset of major SSWs during the winters of 2003/04, 2005/06 and 2008/09. Sofieva et al. (2012) used Global Ozone Monitoring by Occultation of Stars (GOMOS) satellite measurements to study the $\mathrm{O}_{3}, \mathrm{NO}_{2}$ and $\mathrm{NO}_{3}$ distribution during the three major SSWs and found that changes in chemical composition due to major SSWs can extend into the mesosphere and even into the lower thermosphere. Manney et al. (2015) studied the winter of 2012/13 and pointed out that, although the chlorine-induce ozone loss became weak after the onset of SSW, the ozone loss was still significant due to the unusual low temperature in the lower stratospheric polar vortex and continued confinement of air in the vortex mainly in December and January.

From the Lagrangian perspective, modelling of transport can be divided into advection and mixing. Advection is the reversible part of transport which describes transport of an air parcel along a 3-D trajectory. Mixing, the irreversible part of transport, makes the representation of transport barriers in Eulerian models difficult (Sankey and Shepherd, 2003; Hegglin and Shepherd, 2007; Hoppe et al., 2014). Compared to Eulerian transport models with an implicit numerical diffusion, Lagrangian transport models have advantages in separating mixing from advection, and thus explicitly describe the mixing process in the atmosphere. Here, we use the Chemical Lagrangian Model of the Stratosphere (CLaMS), which is a chemistry transport model with Lagrangian transport and parametrized mixing induced by atmospheric deformation (McKenna et al., 2002b; Konopka et al., 2004, 2007). The concept of deformation-induced mixing parameterization is based on the concept that horizontal flow deformation produces pronounced filaments and streamers in the stratosphere, which induce non-linear behaviour on small scales with subsequent mixing. Advection in CLaMS is driven by the European Centre for Medium-range Weather Forecasts (ECMWF) ERA-Interim reanalysis horizontal winds $u, v$, and cross-isentropic vertical velocity is deduced from diabatic heating rates (Dee et al., 2011; Ploeger et al., 2010).

An appropriate representation of mixing in the models is one main difficulty for an accurate description of the permeability of transport barriers like the polar vortex edge or the tropical pipe (Tuck, 1986; Plumb, 1996; Steinhorst et al., 2005; Hoppe et al., 2014). Mixing itself is an irreversible process which, in a stably stratified stratosphere, is mainly driven by isentropic stirring that is associated with largescale wave breaking and wind shear (McIntyre and Palmer, 1983). Riese et al. (2012) assessed the influence of uncertainties in the atmospheric mixing strength on the global distribution of the greenhouse gases $\mathrm{H}_{2} \mathrm{O}, \mathrm{O}_{3}, \mathrm{CH}_{4}$ and $\mathrm{N}_{2} \mathrm{O}$ in the upper troposphere and lower stratosphere (UTLS) and on the associated radiative effects. Their results show that simulated radiative effects of $\mathrm{H}_{2} \mathrm{O}$ and $\mathrm{O}_{3}$, both characterized by steep gradients in the UTLS, are particularly sensitive to the atmospheric mixing strength.

To separate and quantify the impact of mixing on transport and chemistry of stratospheric constituents during a SSW, we utilize tracer-tracer correlations. Chemical constituents in the stratosphere whose chemical sources and sinks are slow compared with dynamical timescales, are influenced by the Brewer-Dobson circulation and by quasi-isentropic mixing (which is most efficient within the extratropical surf zone in winter) and show compact tracer-tracer relations (Plumb, 2007). Mixing is suppressed at the edge of the winter polar vortex and at the edges of the tropics, so that tracer relationships distinct from those of middle latitudes occur in the tropics and in the polar vortices (e.g. Plumb, 1996; Volk et al., 1996; Müller et al., 1996, 2001; Plumb, 2007). Here, we focus on the relationship of $\mathrm{O}_{3}$ with the long-lived tracer $\mathrm{N}_{2} \mathrm{O}$. Because chemical production and loss terms of $\mathrm{O}_{3}$ increase strongly with altitude in the stratosphere, ozone can not be considered long-lived at altitudes above $\approx 20 \mathrm{~km}$ and relations with $\mathrm{N}_{2} \mathrm{O}$ are not necessarily compact (Hegglin 
and Shepherd, 2007). Conditions are different in the polar vortex in winter, where the lifetime of ozone exceeds half a year in the absence of chlorine-catalyzed ozone loss in the lower stratospheric vortex (Sankey and Shepherd, 2003). However, the transport barriers in the stratosphere are sufficiently strong to allow distinct tracer-tracer relationships, in particular different $\mathrm{O}_{3}-\mathrm{N}_{2} \mathrm{O}$ relationships to develop in the polar vortex, the mid latitudes and in the tropics (Michelsen et al., 1998; Ray et al., 2002; Müller et al., 2005; Hegglin and Shepherd, 2007).

Because different $\mathrm{O}_{3}-\mathrm{N}_{2} \mathrm{O}$ relationships prevail in the polar vortex, in mid latitudes and in the tropics, mixing of air masses from these different regions will change $\mathrm{O}_{3}-\mathrm{N}_{2} \mathrm{O}$ relationships, even if relations in a particular region are linear (Fig. 1, top panel). Mixing between the polar vortex and mid latitudes and between mid latitudes and the tropics occurs along quasi-isentropic surfaces (Proffitt et al., 1990; Müller et al., 2005). Because of the location of the isentropes in $\mathrm{O}_{3}-$ $\mathrm{N}_{2} \mathrm{O}$ space, mixing of mid-latitude and polar air will lead to higher ozone and higher $\mathrm{N}_{2} \mathrm{O}$ in the polar region, and mixing of mid-latitude and tropical air will lead to lower $\mathrm{N}_{2} \mathrm{O}$ and lower ozone in the tropics (Fig. 1, top panel). The effect of mixing between polar and mid-latitude air on $\mathrm{O}_{3}-$ $\mathrm{N}_{2} \mathrm{O}$ relationships and the occurrences of this process along quasi-isentropic surfaces is also clearly visible in model simulations (Sankey and Shepherd, 2003; Müller et al., 2005; Lemmen et al., 2006). However, the strength of the transport barrier at the vortex edge is likely underestimated in model simulations (Hoppe et al., 2014) so that the intensity of mixing will be overestimated.

Upwelling and downwelling of stratospheric air changes tracer mixing ratios at a particular altitude (or potential temperature level) but does not change the tracer-tracer correlation (Ray et al., 2002). Therefore $\mathrm{O}_{3}-\mathrm{N}_{2} \mathrm{O}$ relationships will not be affected by up- and downwelling (Fig. 1, middle panel), while however the location of the potential temperature surfaces in $\mathrm{O}_{3}-\mathrm{N}_{2} \mathrm{O}$ space will change. Because of the vertical profile of ozone and $\mathrm{N}_{2} \mathrm{O}$ below altitudes of $\approx 700 \mathrm{~K}$, downwelling in the polar region will lead to an upward bending (more ozone, less $\mathrm{N}_{2} \mathrm{O}$ ) of the isentropes, while upwelling in the tropics will lead to downward bending (less ozone, more $\mathrm{N}_{2} \mathrm{O}$ ) of the isentropes (Fig. 1, middle panel, grey lines).

Finally, chemistry will impact $\mathrm{O}_{3}-\mathrm{N}_{2} \mathrm{O}$ relationships; indeed ozone-tracer relations have been used extensively to examine lower stratospheric ozone loss in the polar regions (e.g. Proffitt et al., 1990; Müller et al., 1996, 2001; Tilmes et al., 2006). On the timescales and for the altitudes of interest here, only chemical change for ozone needs to be taken into account. Thus, chemical loss of ozone in the polar regions shifts the $\mathrm{O}_{3}-\mathrm{N}_{2} \mathrm{O}$ relationship downward, towards lower ozone mixing ratios and chemical production of ozone in the tropics will shift the $\mathrm{O}_{3}-\mathrm{N}_{2} \mathrm{O}$ relationship upwards towards higher ozone mixing ratios (solid and dashed black lines in Fig. 1, bottom panel). In a model simulation the im-

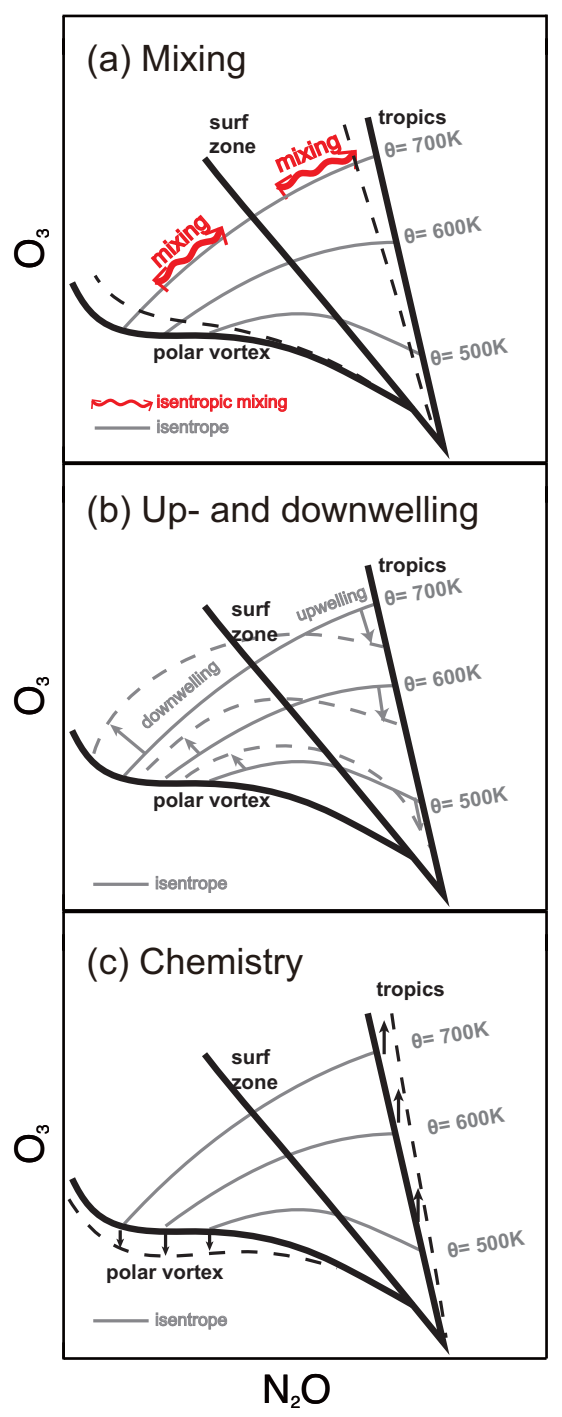

Figure 1. Schematic diagram showing the influences of (a) mixing, (b) up- and downwelling and (c) chemistry on $\mathrm{N}_{2} \mathrm{O}-\mathrm{O}_{3}$ correlations.

pact of chemistry on ozone-tracer relations can be investigated further through simulations using passive (i.e. chemically inert) ozone; this point will be discussed below in Sect. 5.

The motivation of this work is to improve our understanding of transport and its impact on chemistry in the stratosphere under strongly disturbed dynamical conditions. In particular, the 2009 major SSW is an excellent case for studying: (1) the multi-timescale (days to months) responses to the wave forcing; (2) the evolution of mixing and its effect on distribution of chemical composition; and (3) the observed tracer-tracer correlations using CLaMS simulations. In Sect. 2, we will present an overview of the dynamical background of the stratospheric winter 2008/09. The CLaMS setup and validation of CLaMS result with the MLS obser- 
vations of $\mathrm{N}_{2} \mathrm{O}$ and $\mathrm{O}_{3}$ will be presented in Sect. 3. Section 4 will discuss the simulated mixing intensity in relation to wave forcing. Finally, Sect. 5 will present the $\mathrm{N}_{2} \mathrm{O}-\mathrm{O}_{3}$ correlations and their interpretation in terms of mixing, advection and chemistry caused by the major SSW in January 2009. Finally, the main results will be concluded in Sect. 6 .

\section{Dynamical background}

The definitions for SSW and classifications are extensively discussed by Butler et al. (2015). According to commonly used criteria (Christiansen, 2001; Charlton and Polvani, 2007), we identify the warming event on 24 January by the reversal of $60^{\circ} \mathrm{N}$ westerly zonal-mean wind at $10 \mathrm{hPa}$. As has been pointed out (Taguchi, 2011; Gómez-Escolar et al., 2014), use of the highest polar cap temperature instead of the zonal wind reversal at $60^{\circ} \mathrm{N}$ and $10 \mathrm{hPa}$, characterizes the response of the BDC to SSWs better. Thus, we identify the central SSW day as the date when 5-day smoothed polar cap temperature at $10 \mathrm{hPa}$ reach its peak within \pm 5 days of the wind reversal date. 23 January is used as the central day in our study because the polar cap temperature reached its peak on 23 January.

Figure 2 gives an overview of the dynamical background during the boreal winter 2008/09 based on ERA-Interim reanalysis. Figure $2 \mathrm{a}$ shows that the sudden rise of the polar cap temperature started in the upper stratosphere, around 10 January at $1 \mathrm{hPa}$. Thereafter, the warming propagated downward, arriving at $10 \mathrm{hPa}$ and descended to the lower stratosphere until late January. The increase of polar temperature was accompanied by the generation of easterlies, which are also shown in Fig. 2a (black contours). The rise in easterlies and temperature lasted only 10 days at $1 \mathrm{hPa}$ followed by a strong polar vortex cooling while the disturbance of wind and temperature in the lower stratosphere lasted more than 1 month without a complete recovery until the final warming in the spring of 2009.

Before the major SSW, the lower stratosphere in the tropics was slightly warmer than the long-term average due to the westerly phase of the QBO in this winter. Similar to the warming in the high latitudes, the tropical cooling (Fig. 2b) also started at about 15 January at $1 \mathrm{hPa}$ and descended from the upper to the lower stratosphere over 2 weeks. As discussed in Randel et al. (2002), time-dependent upwelling in the tropical lower stratosphere is correlated with transient extratropical planetary waves, which transport heat from the tropics to high latitudes and, in turn, drive the BDcirculation.

A widely used diagnostic of the upward-propagating planetary waves is the vertical component of the EP flux, for which the strongest contribution results from the horizontal eddy heat flux $\overline{v^{\prime} T^{\prime}}$ with $v^{\prime}=v-\bar{v}, T^{\prime}=T-\bar{T}$ and with the overbar denoting zonal mean and primes describing the deviations (i.e. fluctuations) for the temperature $T$ and for the
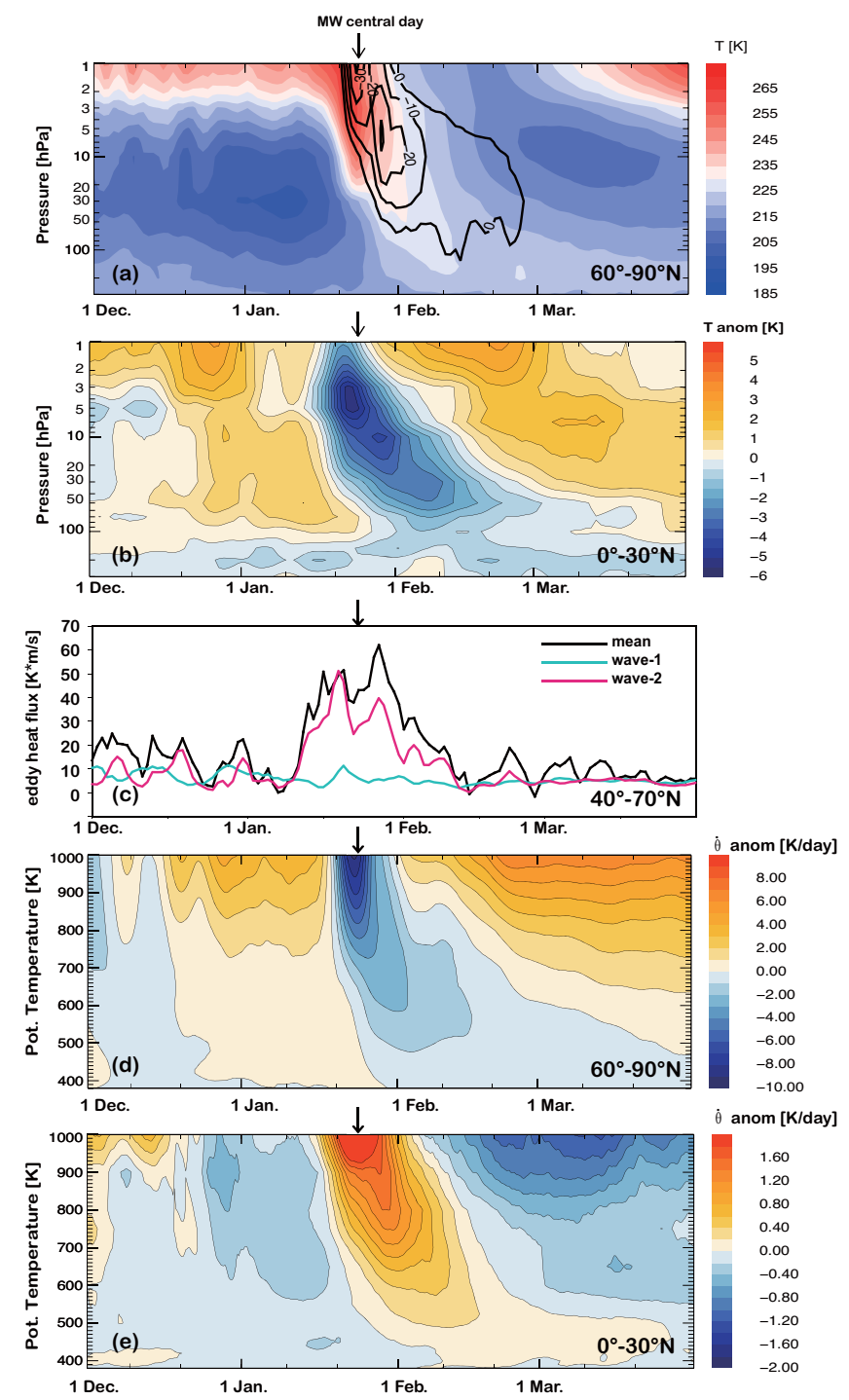

Figure 2. (a) Polar cap area weighted mean temperature $\left(60-90^{\circ} \mathrm{N}\right)$ overlaid with zonal mean easterlies at $60^{\circ} \mathrm{N}$ (black contours in $\mathrm{m} \mathrm{s}^{-1}$ ), (b) tropical zonal mean temperature anomaly from the 24year climatology $\left(0-20^{\circ} \mathrm{N}\right)$, (c) eddy heat flux $\left(40-70^{\circ} \mathrm{N}\right.$, black) on $100 \mathrm{hPa}$ and its decomposition into wave-1 (blue) and wave-2 (red) components $\left(\right.$ d) polar mean $\left(60-90^{\circ} \mathrm{N}\right)$ anomaly of the heating rates from the 24-year climatology $Q=\mathrm{d} \theta / \mathrm{d} t=\dot{\theta}$ (for more details see the text), (e) same as (d) but for $0-30^{\circ} \mathrm{N}$. The figures are based on the ERA-Interim reanalysis.

meridional velocity $v$ (Andrews et al., 1987; Newman et al., 2001). Figure 2e shows the time evolution of the eddy heat flux at $100 \mathrm{hPa}$ averaged between 40 and $70^{\circ} \mathrm{N}$, which explains more than $80 \%$ of the variability of the total vertical component of the EP flux. In addition, contributions of the wave- 1 and wave- 2 components to the mean eddy heat flux are also shown. 
Newman et al. (2001) pointed out that the eddy heat flux measures activity of the waves and is highly correlated with the time evolution of the stratospheric polar temperature. As can be deduced from Figs. 2e and 2a (or Fig. 2b), the mean eddy heat flux at $100 \mathrm{hPa}$ was well correlated with warming at the North Pole and cooling in the tropics. It shows a 1-2 weeks oscillation ranging within $0-25 \mathrm{~K} \mathrm{~m} \mathrm{~s}^{-1}$ in December and it began to increase from 6 January reaching the first peak on 18 January. After several days of a slight decay, it rose up to the second peak on 27 January and then gradually declined to zero around mid-February with some small fluctuations afterwards. The dominant wave number before and during the major SSW was wave-2, which led to the vortex split. The dominant and extraordinary planetary wave- 2 is associated with unusual development of the upper tropospheric ridge over Alaska (Ayarzagüena et al., 2011; Harada et al., 2010). However, after the major SSW, the main contribution to the total eddy heat flux resulted from higher wave numbers.

Large-scale tropospheric waves can propagate upward into the stratosphere through weak westerlies and break at the critical level, disturbing the mean flow (Dickinson, 1968; Matsuno, 1971). Such a transient wave breaking converts the zonal flow momentum to mean meridional circulation, and thus drives the extra-tropical downwelling and tropical upwelling of the BD circulation (e.g. Holton et al., 1995). The temperature perturbations discussed above and shown in Fig. 2a, b result directly from diabatic heating and cooling caused by these wave-driven vertical motions. Subsequently, temperatures gradually relax toward their radiative equilibrium values by additional radiative cooling or heating, causing vertical motion, i.e. down- or upwelling, through isentropic surfaces. The polar and tropical (total) diabatic heating rate anomalies from the 24-year mean of ECMWF meteorological ERA-Interim reanalysis (Dee et al., 2011) are shown in Fig. 2d, e. As expected, diabatic polar downwelling and tropical upwelling (quantified by these heating rates) were both accelerated after the onset of the major SSW. The polar vortex descent rate strongly increased around 25 January up to $15 \mathrm{~K} \mathrm{day}^{-1}$ on $1000 \mathrm{~K}$ and only around $3 \mathrm{~K} \mathrm{day}^{-1}$ on $500 \mathrm{~K}$ during the late January. The variability of polar vortex descent rate reported here is consistent with findings by Manney et al. (2009b) and Lahoz et al. (2011) where the tracer isopleths method based on MLS observations of $\mathrm{N}_{2} \mathrm{O}$, $\mathrm{CO}$ and $\mathrm{H}_{2} \mathrm{O}$ was used. The onset of the heating rate anomalies at each altitude, and thus their downward propagation, is roughly synchronous with the temperature anomalies shown in Fig. 2a, b. The radiative decay of the anomalies takes only about 10 days at $1000 \mathrm{~K}$, but more than 1 month below $500 \mathrm{~K}$. This is consistent with the stratospheric radiative relaxation time inferred from satellite measurements (Mlynczak et al., 1999), which was found to increase from 10 days at $1 \mathrm{hPa}$ to about 100 days at $50 \mathrm{hPa}$. This is also consistent with a strong suppression of planetary-wave propagation into the vortex after the major SSW (Hitchcock and Shepherd, 2013).

\section{Model description and validation}

\subsection{Model setup}

CLaMS is a Lagrangian chemistry transport model that can be run with or without mixing, so that the whole transport is carried out only along 3-D forward trajectories. However, a pure Lagrangian transport approach gives rise to many unrealistic small-scale structures due to lack of mixing (Konopka et al., 2004; Khosrawi et al., 2005). Hence, irreversible smallscale mixing between air parcels (APs) should be considered. With the concept that (small-scale) mixing is driven by large-scale flow deformation, the CLaMS mixing procedure is realized through adaptive re-gridding of the irregular grid. More specifically, the APs are inserted or merged when the distances between the next neighbours increase above or decrease below a critical distance. The critical deformation $\gamma_{\mathrm{c}}$ is defined as $\gamma_{\mathrm{c}}=\lambda_{\mathrm{c}} \Delta t$, with the critical Lyapunov exponent $\lambda_{\mathrm{c}}$ and the advective time step $\Delta t$ set to 1.5 day $^{-1}$ and $24 \mathrm{~h}$, respectively (for more details see McKenna et al., 2002b; Konopka et al., 2004).

CLaMS simulations cover the 2008/09 boreal winter from 1 December 2008 to 1 April 2009 and extend between the Earth's surface and the potential temperature $\theta=$ $2500 \mathrm{~K}$ (i.e. roughly around the climatological position of the stratopause with $p \approx 0.3 \mathrm{hPa}$ ). The horizontal separation of the APs, which was initialized on 1 December, is $70 \mathrm{~km}$ in the $\mathrm{NH}$, where all our results are obtained, and $200 \mathrm{~km}$ in the $\mathrm{SH}$. During the course of the simulation, this irregular grid of APs undergoes advection along the trajectories, chemistry and mixing every time step, with $\Delta t=24 \mathrm{~h}$ (Konopka et al., 2004; Grooß et al., 2005a; Pommrich et al., 2014).

The horizontal winds are prescribed by the ECMWF ERAInterim reanalysis (Dee et al., 2011). To resolve both transport processes in the troposphere influenced by the orography and in the stratosphere where adiabatic horizontal transport dominates, a hybrid coordinate is used as proposed by Mahowald et al. (2002). In the stratosphere and in the UTLS, potential temperature $\theta$ is employed as the vertical coordinate of the model above $300 \mathrm{hPa}$ and the cross-isentropic velocity $\dot{\theta}=Q$ is deduced from the ERA-Interim forecast total diabatic heating rates $Q$, including the effects of all-sky radiative heating, latent heat release and diffusive heating as described by Ploeger et al. (2010). The time evolution of the anomaly of $\dot{\theta}$ averaged over the polar cap and over the tropics is shown in Fig. 2c, $d$ and was discussed in the previous section.

$\mathrm{N}_{2} \mathrm{O}$ and $\mathrm{O}_{3}$, the most important species for this work, are initialized from the MLS data (more details on MLS can be found in the next subsection). The other chemical species are initialized from a multi-annual CLaMS simulation with simplified chemistry (Pommrich et al., 2014) as well as from gridded $\mathrm{MLS}$ data of $\mathrm{HCl}, \mathrm{H}_{2} \mathrm{O}$ and $\mathrm{CO}$. The employed method uses tracer-tracer correlations (for more details see Grooß et al., 2014). At the upper boundary $(2500 \mathrm{~K}) \mathrm{O}_{3}$ is 

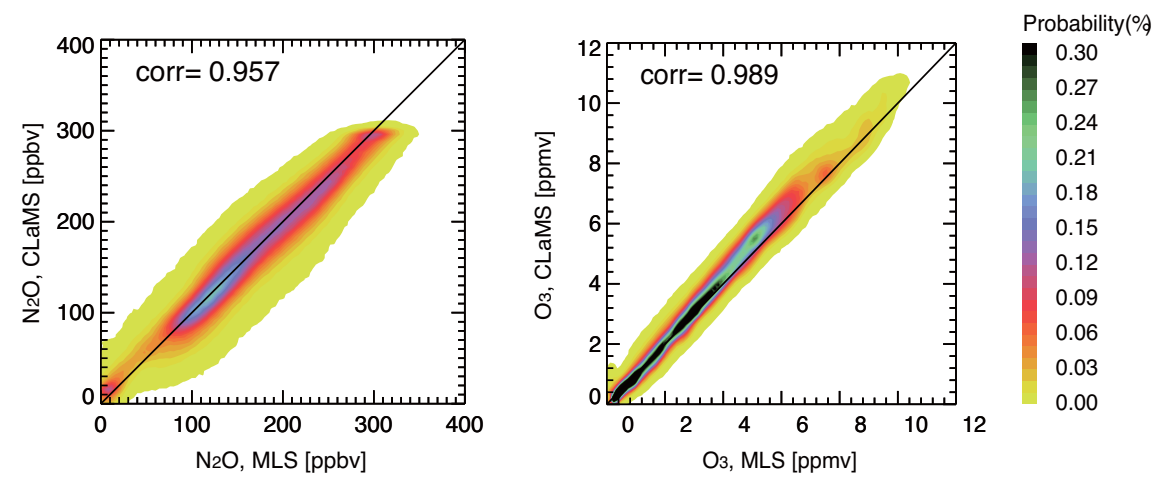

Figure 3. PDFs (probability distribution functions) of MLS observations and CLaMS reference simulation for the entire simulation period from 1 December 2008 to 1 April 2009 for APs in the Northern Hemisphere with $400 \mathrm{~K}<\theta<1000 \mathrm{~K}$ (left: $\mathrm{N}_{2} \mathrm{O}$, right: $\mathrm{O}_{3}$ ).

set to the HALOE climatology after every $24 \mathrm{~h}$ time step. However, the impact of the upper boundary condition on the chemical tracers is not significant below $1000 \mathrm{~K}$ and our following analyses are for levels below $1000 \mathrm{~K}$. The chemistry module of CLaMS is described in detail in McKenna et al. (2002a).

By switching the mixing module off and on, we get two sets of simulations: full chemistry without mixing and full chemistry with mixing. The simulation with full chemistry and with mixing is the reference as the best model representation of the real atmosphere. Both simulations include ozone calculated with full chemistry $\left(\mathrm{O}_{3}\right)$ and passively transported $\mathrm{O}_{3}$ without any chemistry $\left(p \mathrm{O}_{3}\right)$.

\subsection{Validation with the MLS observations}

MLS observes microwave emission from the limb of the Earth's atmosphere in the direction of the Aura orbit. The instrument measures vertical profiles every $165 \mathrm{~km}\left(1.5^{\circ}\right.$ along the Aura orbit), providing about 3500 profiles per day. We use version $3.3 \mathrm{~N}_{2} \mathrm{O}$ and $\mathrm{O}_{3}$ from the MLS product (Livesey et al., 2013) both to initialize and to validate the CLaMS reference simulation. The vertical resolution of $\mathrm{O}_{3}$ is about 2.5$3 \mathrm{~km}$ in the stratosphere with a 5-10\% uncertainty (Livesey et al., 2013). The vertical resolution of $\mathrm{N}_{2} \mathrm{O}$ is about $4-6 \mathrm{~km}$ with a 9-25\% uncertainty for the region of interest in this study (Livesey et al., 2013). Averaging kernels are applied in the retrieval of the MLS profiles, which relate the retrieved MLS profiles to the true atmospheric state.

For comparison, we map CLaMS mixing ratios to the observed MLS profiles using a back and forward trajectory technique (Ploeger et al., 2013) and apply the MLS averaging kernels to CLaMS output in order to get comparable quantities (see Appendix). Because CLaMS APs are saved every day only at 12:00 UTC, we calculate the noon-positions of the MLS observations within a 1-day window using back and forward trajectories, and then select the nearest CLaMS AP to the corresponding MLS observation. The mixing ratios at this AP are then compared with the respective MLS observations.

Hereby, a one-to-one MLS-CLaMS data set for $\mathrm{N}_{2} \mathrm{O}$ and $\mathrm{O}_{3}$ is established that is plotted in Fig. 3 as probability distribution functions (PDFs) calculated for the whole $\mathrm{NH}$ and for the entire simulation period (around 10 thousand points). According to a high correlation coefficient both for $\mathrm{N}_{2} \mathrm{O}$ (0.957) and for $\mathrm{O}_{3}$ (0.989), our reference simulation matches the MLS observations fairly well. The largest difference was diagnosed in the $\theta$-range between 650 and $1000 \mathrm{~K}$ where CLaMS $\mathrm{O}_{3}$ slightly overestimates the MLS observations. Three possible explanations for this small bias are: (1) there was not enough $\mathrm{NO}_{x}$-induced ozone loss; (2) there was too much photolytical ozone production; (3) poleward transport from the tropics was too fast.

For a further comparison, we investigate the horizontal distribution of $\mathrm{N}_{2} \mathrm{O}$. Figure 4 shows the comparison between the CLaMS simulation and MLS observations for five selected days at $\theta=800 \mathrm{~K}$ (top 2 panels) and $475 \mathrm{~K}$ (bottom 2 panels). On 9 January, the vortex was centred around the North Pole and the vortex edge was well defined and not changing rapidly in the middle and lower stratosphere. Mainly influenced by the planetary wave-2, the polar vortex stretched to North America and Asia on both heights during the following days. Around the central day of the major SSW at 23 January, a double centre structure formed which split up until 25 January at $475 \mathrm{~K}$ and until 28 January at $475 \mathrm{~K}$ (not shown).

In the following days, an increasing number of filaments could be observed outside of the vortex characterized by low $\mathrm{N}_{2} \mathrm{O}$ values. The two vortex centres slowly rotated anticlockwise. One of the vortex remnants over eastern North America and the Atlantic stretched further, split and dissolved, releasing its content to mid latitudes, while another one stayed over northern Asia and the Pacific Ocean. Although in the following weeks most of the vortex fragments were mixed with mid-latitude air, a part of them, like those over northern Asia and the Pacific Ocean, re-organized as a new and relatively weak vortex. However, this top-down process that started in 


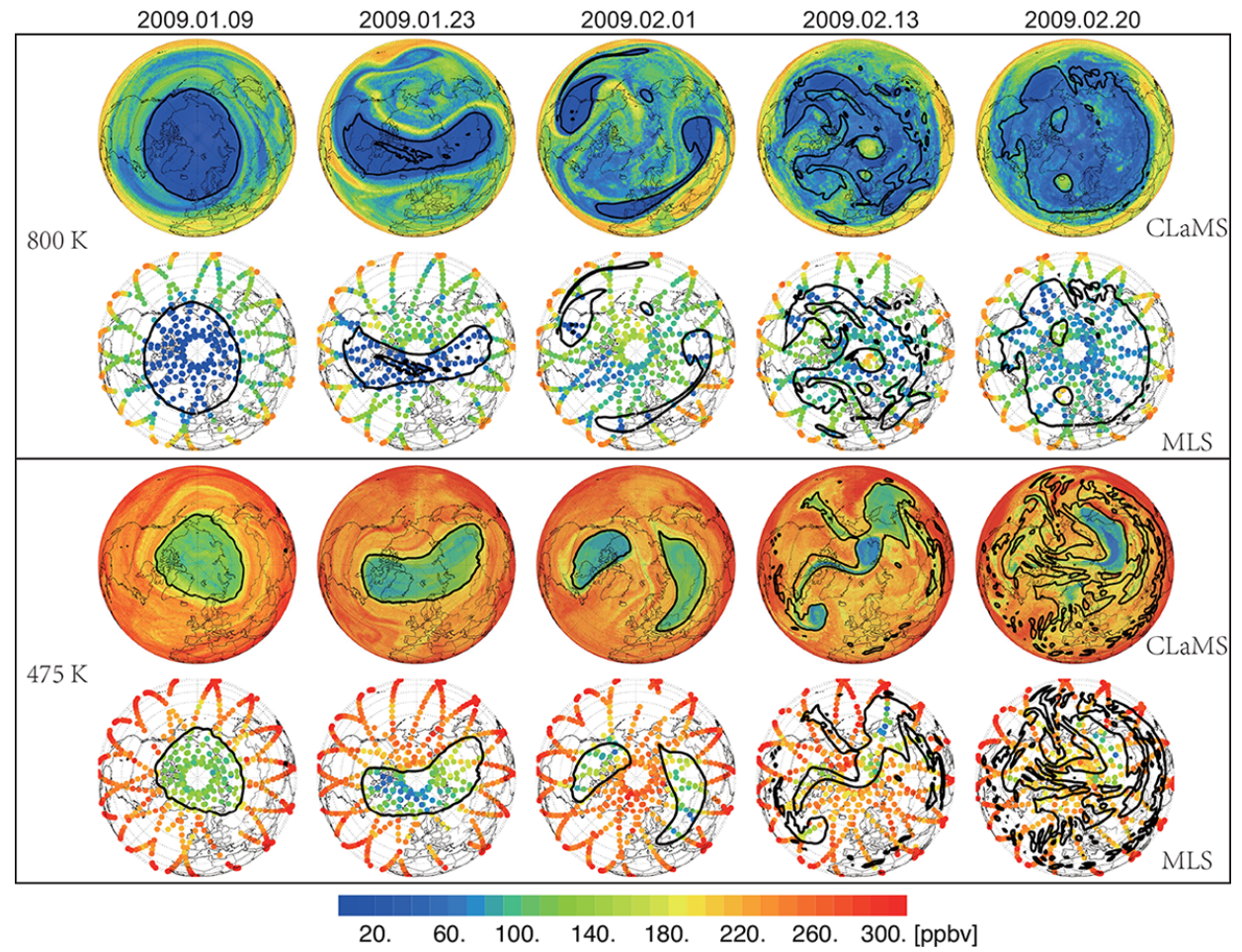

Figure 4. $\mathrm{N}_{2} \mathrm{O}$ distribution at $\theta=800 \mathrm{~K}$ (top 2 rows) and $475 \mathrm{~K}$ (bottom 2 rows) interpolated from CLaMS simulation and MLS observations for five selected days in 2009 before and after the major SSW event. Nash's criteria (Nash et al., 1996) is applied to define the edge of the polar vortex shown as the black contours. According to this method, the vortex edge is identified as the maximum PV (potential vorticity) gradient with respect to equivalent latitude constrained by the location of the maximum wind jet calculated along equivalent latitudes.

late February at $800 \mathrm{~K}$ (a weak, circumpolar vortex edge can be diagnosed at $\theta=800 \mathrm{~K}$ at 20 February, see Fig. 4) and was finished in mid March at $475 \mathrm{~K}$ (not shown), is excluded from our analysis, which ends with 28 February.

The distribution of simulated $\mathrm{N}_{2} \mathrm{O}$ accurately represents the MLS observations, although more filamentary structures are resolved in CLaMS simulations than MLS observations. It should be noted that applying averaging kernels to model result also smoothes out some valuable information, e.g. filamentary structures, and, consequently, may result in a misinterpretation of the stratospheric composition, especially for high-latitude $\mathrm{N}_{2} \mathrm{O}$. More details are discussed in the Appendix.

\section{Planetary waves and mixing}

\subsection{Transport and mixing barriers in the winter hemisphere}

In the winter stratosphere, two main barriers to transport exist, shown by the two thick blue lines in Fig. 5 (Holton et al., 1995). One is the polar vortex edge, which can be identified as the maximum gradient of potential vorticity (PV) with respect to equivalent latitude within a certain range where maximum of wind speed along equivalent latitudes (in the fol- lowing eq. latitude) occurs (Nash et al., 1996). The second barrier (around $10-30^{\circ} \mathrm{N}$ eq. latitude, varying with altitude) separates the mid-latitude surf zone (McIntyre and Palmer, 1983) from the region of tropical upwelling, the so-called tropical pipe (Plumb, 1996).

This subtropical barrier is not as well-defined as the polar vortex edge and is usually characterized by a much weaker PV gradient between tropics and mid latitudes (Polvani et al., 1995) although large meridional tracer gradients can be diagnosed (Shuckburgh et al., 2001; Punge et al., 2009; Konopka et al., 2010). While the polar vortex edge is considered as a meridional transport barrier due to a strong polar jet, the subtropical barrier is only weakly influenced by the jets and is usually understood as a barrier for propagation of planetary waves. This barrier is strongly related to the phase of the quasi-biennial oscillation (QBO): during the westerly QBO, planetary waves generated in the winter hemisphere can propagate across the equator to dissipate at the summer hemisphere easterlies, whereas such propagation is suppressed during the easterly QBO phase (Haynes and Shuckburgh, 2000; Shuckburgh et al., 2001; Punge et al., 2009). Thus, during the 2008/09 winter, the subtropical transport barrier was weakened by the westerly QBO phase (dashed thick blue line in Fig. 5). 


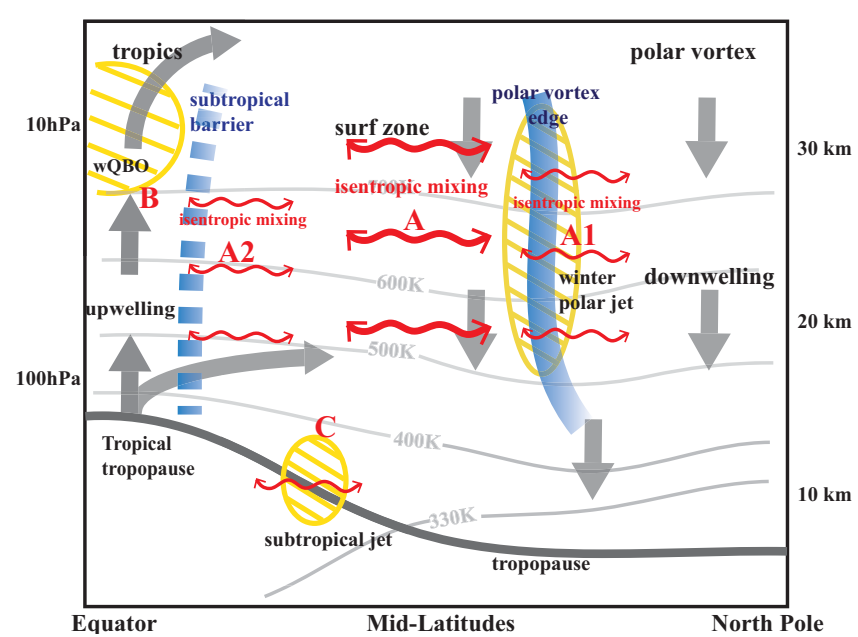

Figure 5. Schematic diagram of transport and mixing processes in the winter stratosphere. The thick blue lines show the barriers, the grey arrows indicate the direction of the BD circulation. Yellow shaded areas stand for strong westerlies. Red two-headed arrows indicate isentropic mixing, with thicker and thinner arrows showing stronger mixing in the surf zone and weaker mixing across the transport barriers, respectively. For a better overview, the tropopause with the subtropical jet are also marked.

In a winter with weak activity of planetary waves and a strong vortex, the exchange and mixing of air across the vortex edge is suppressed. However, once a strong sudden warming event happens that usually follows a significant weakening of vortex edge (with exceptions e.g. 2013 SSW Manney et al., 2015), enhanced wave forcing drives significant isentropic, two-way mixing (red curved arrows) as well as the large-scale BD circulation (grey arrows). The evolution of the dynamical fields, including cross-isentropic vertical velocity $\dot{\theta}$ and zonal wind, was discussed in the previous section (Fig. 2). But isentropic mixing and its relation to wave forcing need further investigation.

\subsection{CLaMS mixing versus wave forcing}

Mixing between the Lagrangian APs is parametrized in CLaMS through adaptive re-gridding. During this process, the involved APs (i.e. APs, which were generated by the mixing algorithm), are marked after every $24 \mathrm{~h}$ time step. Here we use the statistics of these events, i.e. the percentage of mixed APs relative to all transported APs, in the following denoted as mixing intensity. In this way, we illustrate the impact of the major SSW on the distribution and evolution of mixing resolved by the model.

Figure 6 shows the time evolution of the zonally averaged mixing intensity derived from CLaMS versus eq. latitude. Figure 7 illustrates the relationship between the EP flux divergence and the CLaMS mixing intensity averaged over several stages of the polar vortex during the winter of 2008/09: (a) strong vortex conditions in January between 3rd and 13th,

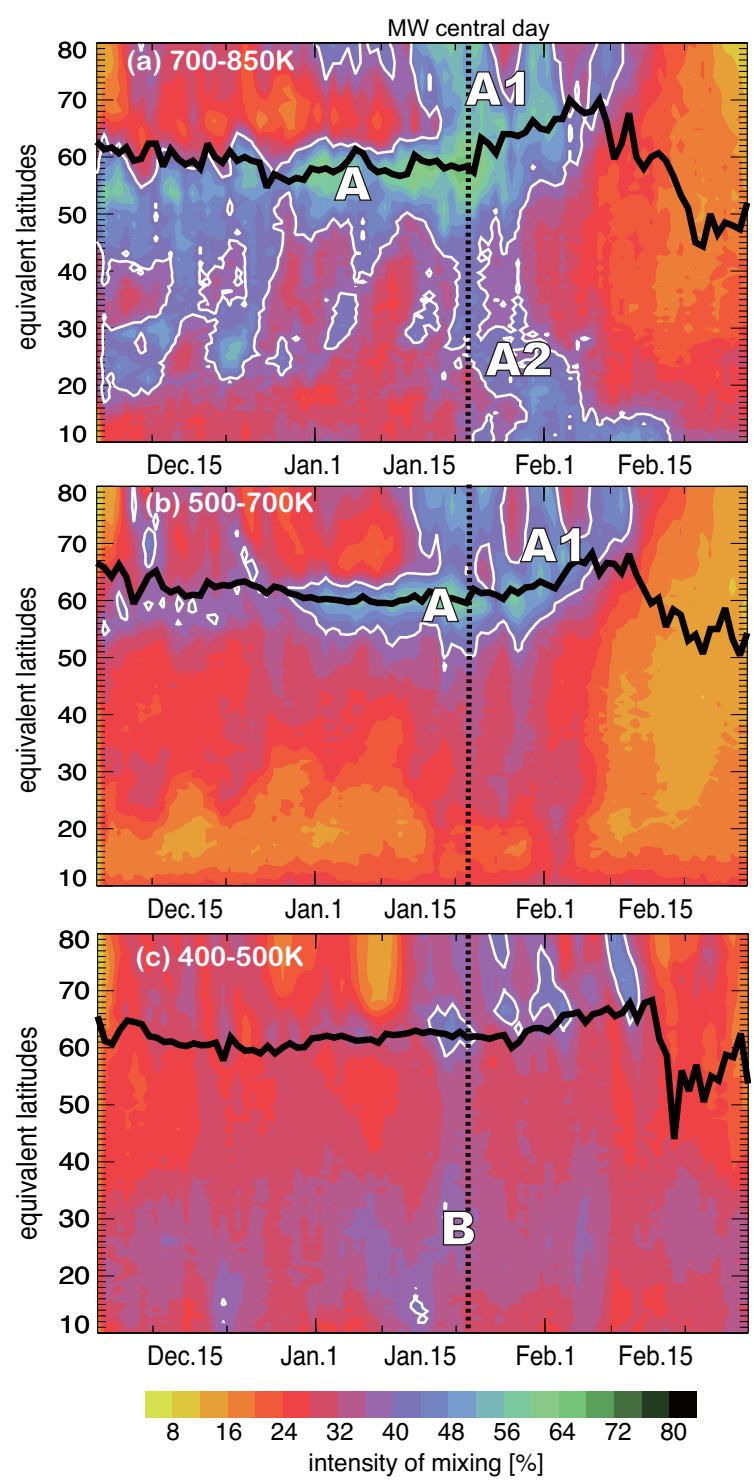

Figure 6. CLaMS zonal mean mixing intensity within three layers: (a) $700-850 \mathrm{~K}$, (b) $500-700 \mathrm{~K}$ and (c) $400-500 \mathrm{~K}$ overlaid by the location of the vortex edge (thick black lines Nash et al., 1996). The white contours indicate the mixing intensity of $40 \%$. The letters mark the regions of high mixing intensity and correspond to the letters in Fig. 7.

(b) 10-day period before the major SSW, i.e. between 14 and 23 January, (c) 10-day period after the major SSW, i.e. between 24 January and 3 February, and (d) weakened wave activities after the major SSW between 4 and 13 February.

We notice that before mid January, maximum mixing remains equatorward of $65^{\circ} \mathrm{N}$ and generally outside the polar vortex boundary as defined by the Nash criterion (Fig. 6). In particular, above $700 \mathrm{~K}$ the rather abrupt poleward decrease in mixing strength clearly marks the polar mixing barrier isolating the core of the stable polar vortex from the surf zone. Note that the Nash criterion is not necessarily a perfect proxy 
(a) Jan.03- Jan.13

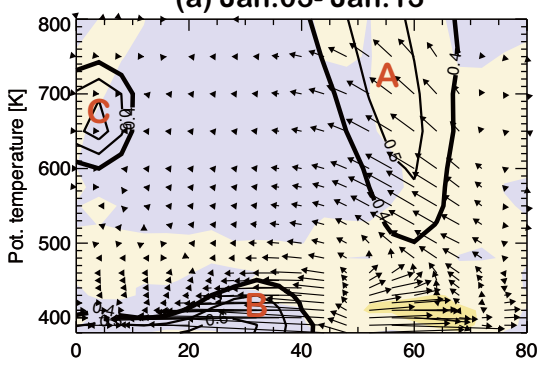

(c) Jan.24- Feb.03

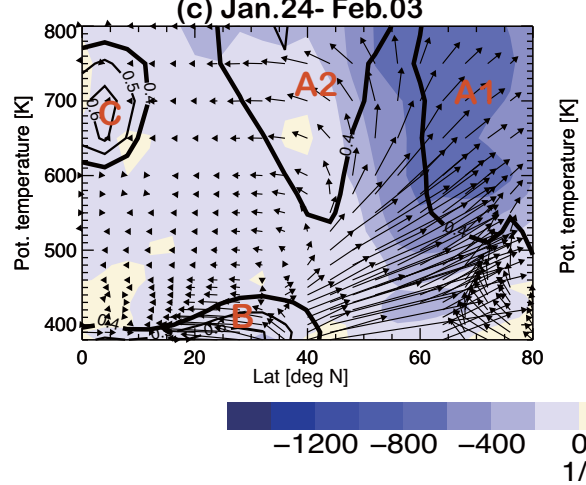

(b) Jan.14- Jan.23

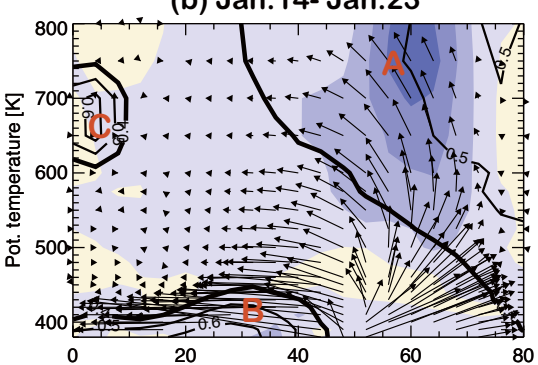

(d) Feb.04- Feb.13

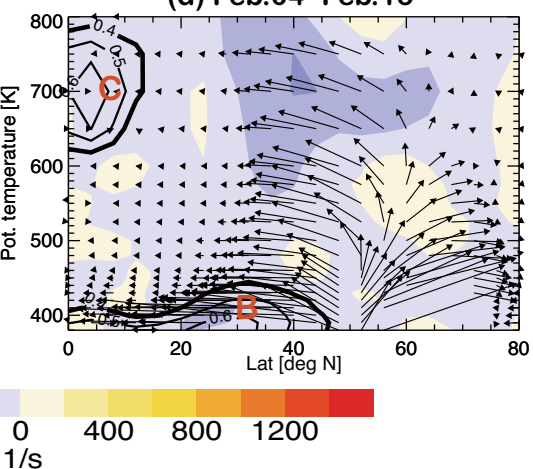

Figure 7. EP flux (arrows) and its divergence (coloured bluish). Black contours indicate the mixing intensity larger than 0.4. The panels (a)-(d) show mean values averaged over four time periods: (a) 3-13 January, (b) 14-23 January, (c) 24 January-3 February and (d) 4-13 February.

for the mixing barrier, thus mismatch to within a few degrees latitude, as apparent in Fig. 6a. In mid January the picture changes drastically. With the intensified wave activity disturbing the polar vortex, the westerlies decelerated. Consequently, the EP flux increased and its divergence became strongly negative, meaning an enhanced convergence of the EP flux (Fig. 7). Furthermore, the pattern of mixing intensity separated into two branches above $700 \mathrm{~K}$ after 24 January (Fig. 6a): one in high and another one in mid eq. latitudes (marked as A1 and A2 in Figs. 6a and 7c, respectively).

This distribution of mixing intensity indicates that both the polar and subtropical barrier (the latter above $700 \mathrm{~K}$ ) are weakened by the major SSW. Furthermore, daily PV or tracer distributions over the NH (cf. Fig. 3) exhibit that at this time several vortex fragments move equatorward and mix with mid-latitude air. At the same time, several fragments of tropical air masses which are generated at low latitudes, are transported poleward and mixed with mid- or high-latitude air.

Mixing intensity diagnosed in Fig. 6 shows some interesting, altitude-dependent patterns: At the highest levels $(\theta$ between 700 and $850 \mathrm{~K}$ ) after the major SSW, the mid- and high-latitude mixing is comparable (cf. A1 versus A2 in Fig. 6a). At the levels between 500 and $700 \mathrm{~K}$, the highlatitude mixing branch within the vortex dominates. Finally, in the lower stratosphere between 400 and $500 \mathrm{~K}$, mixing has intensified in the polar region after the major SSW, while the mixing intensity in the surf zone (marked by B in Fig. 6c) has slightly increased during and after the major SSW. Note that the subtropical barrier can be identified as a minimum in mixing intensity between 10 and $20^{\circ} \mathrm{N}$ eq. latitude (Fig. 6b). The position of this minimum does not significantly change during the time shown although the impact of the major SSW can be seen around 1 February, mainly at highest levels between 700 and $850 \mathrm{~K}$.

From the vertical cross sections of EP flux shown in Fig. 7, we infer that in the first half of January, there were three intensive mixing regions (marked as $\mathrm{A}, \mathrm{B}$ and $\mathrm{C}$ ) with only weak, vertically propagating waves. As mentioned above, region A became stronger during the course of the winter and then divided into two branches (A1 and A2). Region B is related to the mid-latitude (surf zone) mixing in the lower stratosphere $(400-500 \mathrm{~K})$ that is influenced by the subtropical jet and the QBO. Region $\mathrm{C}$ is associated with strong vertical shear in the transition layer between the westerlies and easterlies of the QBO.

It is obvious that although high mixing intensities can be diagnosed in the surf zone outside of the polar vortex (region A) before the major SSW, this signature intensifies after the onset of the major SSW (regions A1 and A2). Convergence of the EP flux indicates breaking of waves and thus leads to wave and mean-flow interaction. Once the local wind field is significantly disturbed by transport of momentum and heat flux, subsequent stirring and stretching of eddies (resolved by the ECMWF winds) drives the mixing parameterization in 
CLaMS. Note that after 10 February (20 days after the SSW), the mixing intensity quickly dropped as the vortex started to recover with a weak vortex edge between 50 and $60^{\circ} \mathrm{N}$ eq. latitude at $800 \mathrm{~K}$ and $50^{\circ} \mathrm{N}$ eq. latitude at $600 \mathrm{~K}$ (i.e. with a weak PV gradient according to the Nash criterion).

Based on the analysis of the temporal and spatial evolution of the mixing intensity resolved in CLaMS and the EP flux divergence, the simulated patterns show a clear and reasonable physical picture how mixing responds to large-scale wave forcing: when the transport barriers stay strong, the mixing pattern does also not change dramatically (Fig. 7a); when the general circulation is disturbed and the transport barriers are weakened, the pattern of mixing is highly associated with the local wave activities (Fig. 7b and c). However, the question still arises whether mixing resolved by the model can also be seen in the observations. This would help to provide a more quantitative understanding of how the major SSW influences the chemical composition of the stratosphere.

\section{Impact of the major SSW on transport and chemistry}

\section{$5.1 \mathrm{~N}_{2} \mathrm{O}-\mathrm{O}_{3}$ correlations: MLS versus CLaMS}

As discussed in the last section, the subtropical barrier and even more so the polar vortex barrier suppress the exchange of air across those barriers before the major SSW. Hence, long-lived species are well-mixed in the regions separated by these barriers and strong isentropic gradients of these species are expected across such barriers. In the tracer-tracer space (in the following abbreviated as tracer space), these wellmixed regions manifest as compact correlations; however correlations between the tracers are different in the regions separated by barriers (for a review of this method see Plumb, 2007).

Figure 9a1-c1 show the $\mathrm{N}_{2} \mathrm{O}-\mathrm{O}_{3}$ correlations of MLS observations plotted as probability distribution functions (PDFs). The data cover the $\mathrm{NH}$ with eq. latitudes between 0 and $90^{\circ} \mathrm{N}$ and within the potential temperature range between 450 and $700 \mathrm{~K}$. The MLS observations are selected for three periods: 18-28 December (1 month before the major SSW), 18-28 January (during the major SSW) and 18-28 February (1 month after the major SSW). The grey lines in Fig. 9a1-c1 indicate the isentropes calculated from the pressure altitude of the observations and corresponding ECMWF temperature.

Under relatively strong vortex conditions before the major $\mathrm{SSW}$, two stronger and one weaker branch of $\mathrm{N}_{2} \mathrm{O}-\mathrm{O}_{3}$ correlations with enhanced PDF values can be distinguished in Fig. 9a1. These branches describe the well-mixed air masses within the polar vortex, the surf zone and the tropics (thin black lines from bottom to the top, respectively). The corresponding barriers in the physical space, i.e. the vortex edge and the subtropical barrier, manifest in tracer space as regions with lower PDF values separating the correlation branches (a detailed discussion follows in the next subsection). After the major SSW (see Fig. 9c1), the polar correlation totally disappears in tracer space and the tropical correlation becomes slightly weaker. Conversely, the PDF of the mid-latitude correlation strengthens in the time period after the major SSW.

\subsection{Tracer and physical space}

Before transport and chemistry triggered by the major SSW in January 2009 is described more quantitatively, Fig. 8 shows schematically how these physical processes can be interpreted and separated by using $\mathrm{N}_{2} \mathrm{O}-\mathrm{O}_{3}$ correlations. The left column in Fig. 8 show the APs in physical space using eq. latitudes as the meridional axis. On the right side, the corresponding tracer space is shown in the same way as discussed in Fig. 1.

Through isentropic mixing, the APs in the mid latitudes change their composition as they mix with other APs isentropically transported from higher or lower latitudes (like fragments B, E and F in Fig. 8a1, b1). Consequently, mixing lines connecting the isolated correlations may appear or, when intensive and persistent mixing happens, the whole correlation line inclines to one side (e.g. the thick black correlations in Fig. 8b2). Moreover, the enhanced mixing also results in a decay or growth of certain correlation branches (shown as thinned or thickened black curves in Fig. 8b2 and c2) and expressing the shrinking or expanding of corresponding regions.

Conversely, if the APs are affected purely by vertical transport like strong cross-isentropic motion during the SSW (i.e. by up- or downwelling), the composition of the APs (and thus their position in tracer space) stays the same although their $\theta$-coordinate significantly changes. As discussed in Fig. 1a, b, in the absence of mixing and chemistry, an AP will not change its coordinates in the tracer space although it will move in the physical space (e.g. vertical displacement of APs shown in Fig. 8b1). Furthermore, if only APs within a limited range of potential temperature are considered, the cross-isentropic transport results in an additional flux of the APs out of (export) or into (import) the considered domain in tracer space. Such vertical export or import of APs reflects in tracer space as vanishing or growing of certain part of the correlation line (vanished parts of vortex correlation are shown as dashed black curves in Fig. 8b2/c2). In the same way, export or import of APs from a limited range of latitudes (or eq. latitudes) may influence the tracer-tracer correlation, e.g. if the subtropical barrier moves toward the equator.

Generally, the major SSW itself creates vortex fragments which in the time following can either merge and reform a new polar vortex, or can be isentropically mixed with the mid-latitude air. These two possibilities are exemplarily shown in Fig. 8b1 and c1 (mixing - fragments B and $\mathrm{E}$; recovery - fragments $\mathrm{A}, \mathrm{C}$ and $\mathrm{D}$ ). Note that in the 


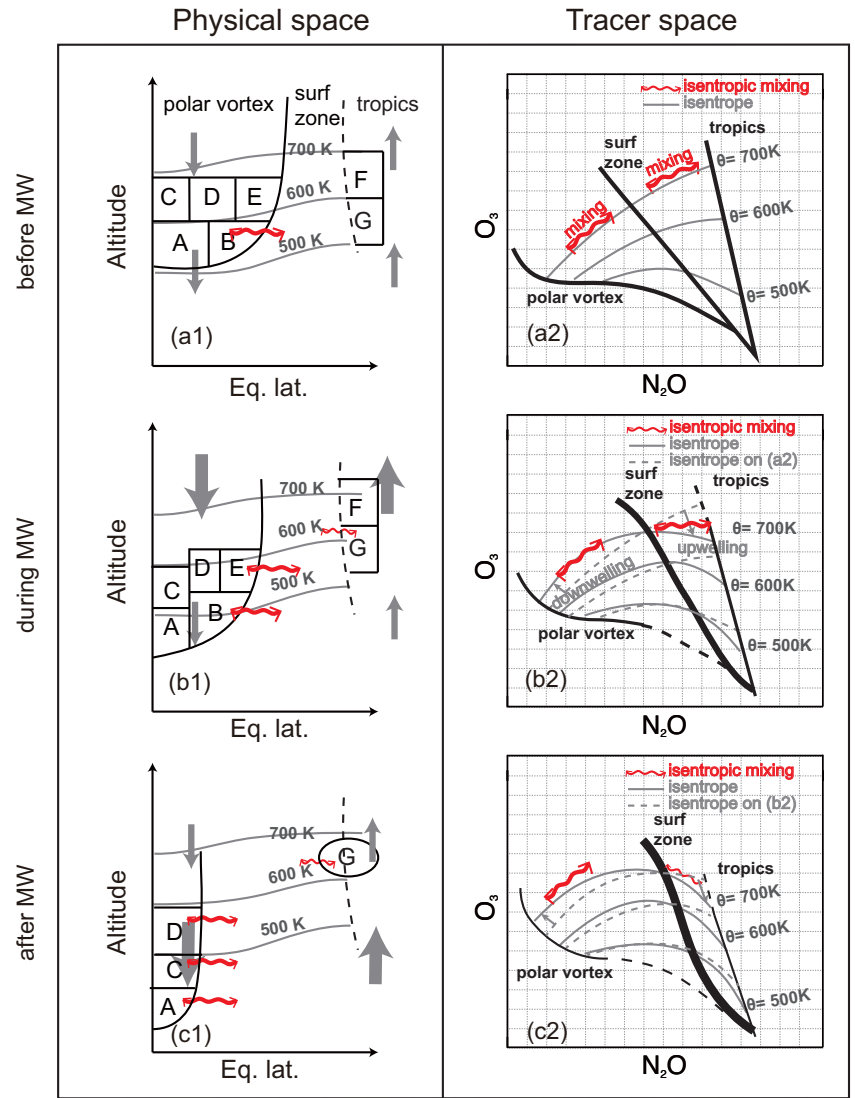

Figure 8. Schematic diagram of transport processes shown in physical space (left column) and tracer space $\left(\mathrm{N}_{2} \mathrm{O}-\mathrm{O}_{3}\right.$, right column) before (top), during (middle) and after (bottom) the major SSW. In the physical space (left column), equivalent latitudes are used as the horizontal coordinates to illustrate isentropic mixing (curved red arrows) and cross-isentropic transport (grey vertical arrows). The thickness of the grey arrows indicates the intensity of vertical motion. The characters denote exemplarily the vortex and tropical air masses which interact with the mid-latitude air. Black curves in (a2)-(c2) show respective $\mathrm{N}_{2} \mathrm{O}-\mathrm{O}_{3}$ correlations. Grey lines denote the isentropic levels. In the tracer space, the position of isentropes before (dashed) and after (solid) the major SSW is also marked. The change of the position of a prescribed point in the tracer space along the isentropes quantifies isentropic mixing, whereas motion relative to these isentropes describes the effect of an idealized (mixing-free) cross-isentropic motion (up- or downwelling). Changes of the relative thickness of the different correlation branches mean their enhanced or weakened relative contributions to the composition of the considered part of the atmosphere (dashed lines indicate a possible missing part).

eq. latitude space, the spatially separated vortex remnants form a compact and coherent circumpolar structure although smaller than the vortex at the beginning of the winter. Finally, also chemistry can influence the $\mathrm{N}_{2} \mathrm{O}-\mathrm{O}_{3}$ correlations as discussed in Fig. 1c. Particularly, halogen or $\mathrm{NO}_{x}$-induced ozone loss would shift the polar or the surf zone correlations downwards, whereas ozone production in the low latitudes would steepen the tropical or the surf zone correlations.

Our first goal is to understand the changes in the $\mathrm{N}_{2} \mathrm{O}$ $\mathrm{O}_{3}$ correlations observed by MLS before and after the major SSW (Fig. 9a1 to c1) as a result of different transport mechanisms (isentropic mixing, meridional transport). In particular, we would like to figure out why the polar and the tropical $\mathrm{N}_{2} \mathrm{O}-\mathrm{O}_{3}$ correlations weakened after the major SSW and the mid-latitude correlation became stronger. First, we rule out ozone chemistry by using CLaMS simulations with passively transported $\mathrm{O}_{3}\left(p \mathrm{O}_{3}\right)$. At the end of this section, we will also include CLaMS results with the full stratospheric ozone chemistry.

\subsection{Isentropic mixing versus cross-isentropic transport}

Two sets of CLaMS simulations, with and without mixing, are used to study the mixing-induced differences between the PDFs of the $p \mathrm{O}_{3}-\mathrm{N}_{2} \mathrm{O}$ correlations. The results are shown in Fig. 9 (middle/bottom row for mixing/non-mixing cases). As in Fig. 9a1-c1, the PDFs are calculated for the same time periods before, during and after the major SSW (from a to c). However, the range of the considered eq. latitudes is confined to $40-90^{\circ} \mathrm{N}$ (instead of $0-90^{\circ} \mathrm{N}$ shown in Fig. 9a1 to $\mathrm{c} 1$ ) to separate more clearly the effect of transport from the tropics on the composition of air in the mid latitudes (see discussion below). To provide better comparability, correlation branches of the non-mixing experiment are also depicted in the mixing case as dashed lines (and vice versa).

\subsubsection{Transport from the tropics}

By using such a limited range of eq. latitudes, we exclude the APs on the tropical side of the subtropical barrier (that is around $20^{\circ} \mathrm{N}$ eq. latitude) and it is obvious that the PDFs of the CLaMS run with mixing do not show any tropical correlation in the eq. latitude $40-90^{\circ} \mathrm{N}$ (Fig. 9a2 to c2). However, a tropical correlation was found in the non-mixing run during and after the major SSW (Fig. 9b3/c3) because in this idealized simulation, tropical air was transported into the mid latitudes but it had not been mixed. For a better comparison, this "artificial" tropical correlation (i.e. from Fig. 9b3/c3) is also shown in Fig. 9b2/c2 (solid dashed line).

Thus, a clear difference in the result of the mixing and nonmixing case indicates that the tropical APs are transported from lower latitudes to mid latitudes where they mix with the mid-latitude APs. Consequently, the slope of the surf-zone correlation moves towards the tropical correlation branch, especially between 550 to $650 \mathrm{~K}$ (cf. Fig. 9 from a 2 to $\mathrm{c} 2$ and $\mathrm{c} 2$ with c3). This isentropic mixing in mid latitudes is also consistent with the increased mixing intensity marked as A2 in Figs. 6 and 7. In contrast, an idealized, pure trajectory calculation (i.e. CLaMS without mixing) completely neglects this effect and produces $\mathrm{N}_{2} \mathrm{O}-\mathrm{O}_{3}$ correlations which cannot 

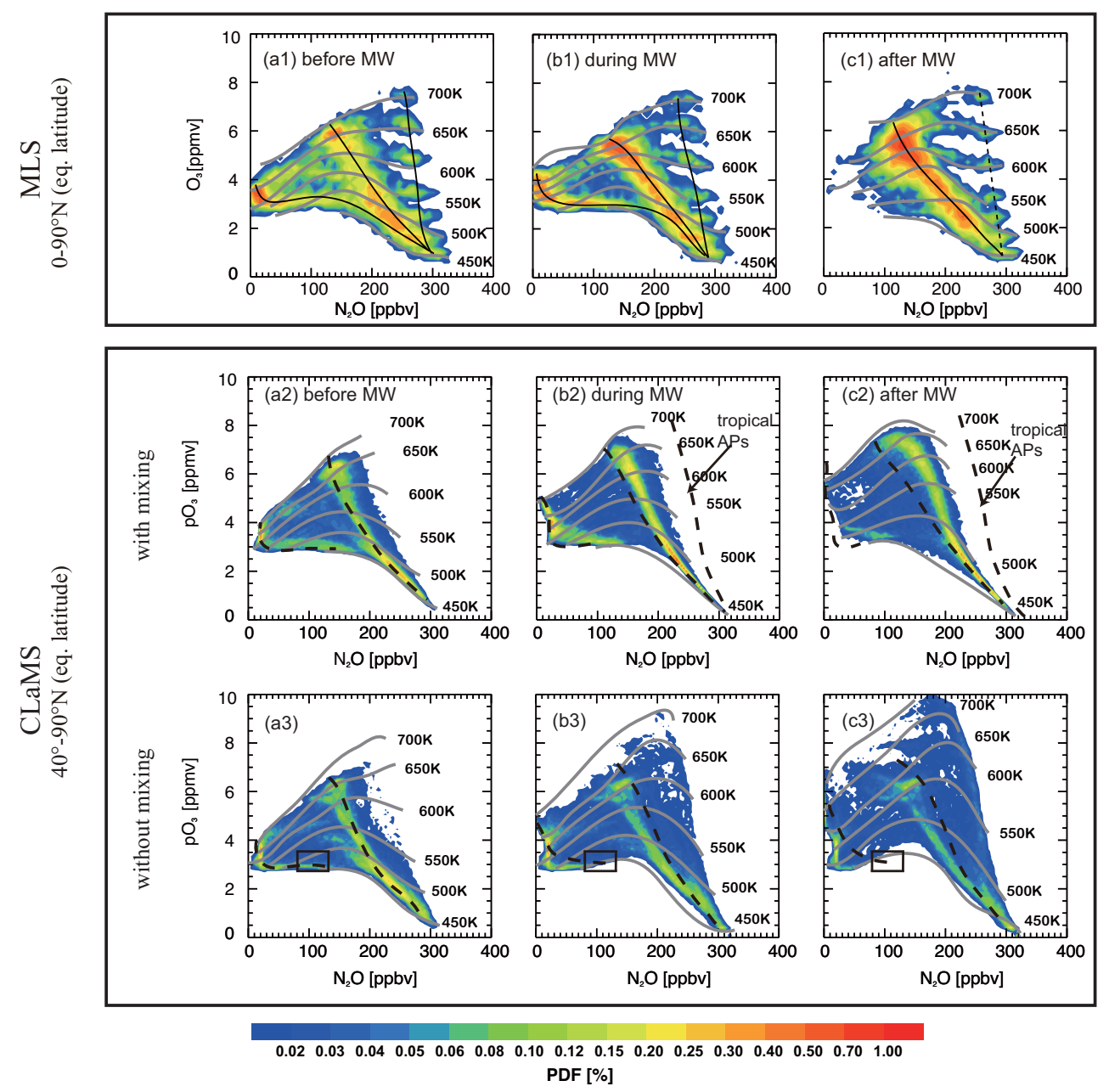

Figure 9. PDFs of $\mathrm{N}_{2} \mathrm{O}-\mathrm{O}_{3}$ correlations (tracer space) shown for three periods: (a) 18-28 December, (b) 18-28 January and (c) 18-28 February. The top row (a1-c1) is based on the MLS observations within eq. latitudes $0-90^{\circ} \mathrm{N}$ and potential temperature range between 450 and $700 \mathrm{~K}$. The black lines in (a1-c1) represent the respective correlation branches (polar, surf-zone, tropics). The middle and bottom rows show CLaMS simulations without ozone chemistry but with and without mixing, respectively. CLaMS PDFs are calculated from the APs with the same potential temperature range but with eq. latitudes between 40 and $90^{\circ} \mathrm{N}$. The grey lines mark the isentropes (450, 500 , $550,600,650$, and $700 \mathrm{~K}$ ). For better comparison between CLaMS with and without mixing, the dashed black curves in (a2-c2) show the estimated $\mathrm{N}_{2} \mathrm{O}-\mathrm{O}_{3}$ correlation line from the case without mixing (i.e. from a3-c3). Reversely, dashed lines in (a3-c3) depict schematically transferred correlation branches from CLaMS with mixing (i.e. from a2-c2).

be reconciled with MLS observations (i.e. for eq. latitudes $40-90^{\circ} \mathrm{N}$, not shown).

\subsubsection{Vortex breakup and decay}

All APs which are transported along the trajectories without mixing do not change their composition and thus keep the same position in the $\mathrm{N}_{2} \mathrm{O}-\mathrm{O}_{3}$ space unless they leave the considered range of eq. latitudes or potential temperatures. Besides the almost isentropic import of tropical APs that was mentioned in the last subsection, strong downwelling within the polar vortex, mainly during the major SSW itself, can also be diagnosed in the tracer space.
The isentropes move upwards in tracer space during the major SSW (Fig. 9 from column a to b), as a consequence of diabatic cooling (downwelling) associated with warming in mid and high latitudes (see also Fig. 8). As a result of this cross-isentropic transport, the APs transported without mixing may be exported (or imported) from (or into) the considered $\theta$-range between 450 and $700 \mathrm{~K}$. For example, the polar APs within the black solid squares in Fig. $9 \mathrm{a} 3$ are missing in the box of Fig. 9c3. The box is defined by the $\mathrm{N}_{2} \mathrm{O}$ values between 80 and 130 ppbv and $\mathrm{O}_{3}$ between 2.7 and 3.5 ppmv. Note that for CLaMS with mixing these regions are filled with APs indicating that mixing in the model re-establishes parts of the correlation. 


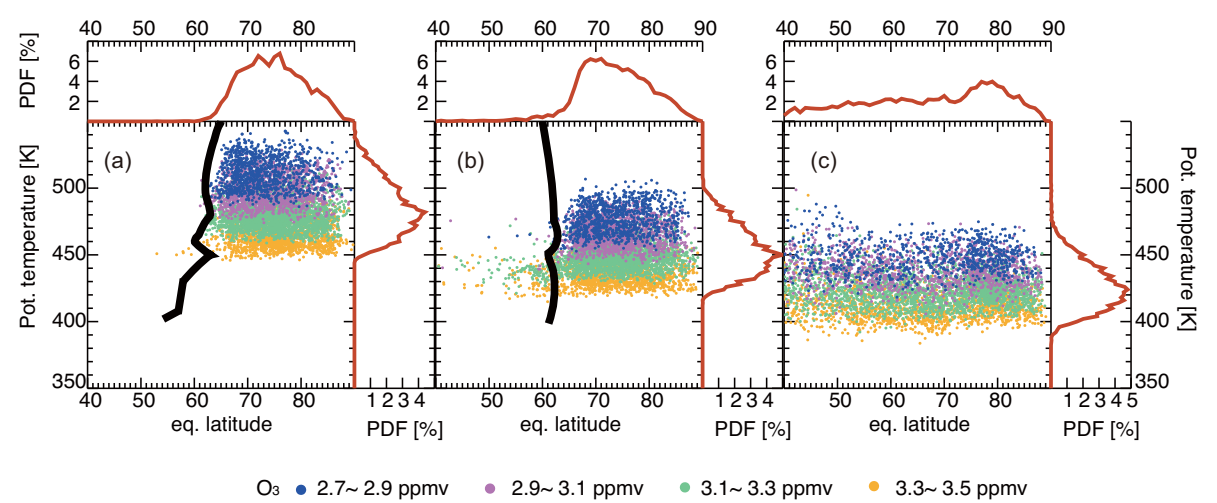

Figure 10. Spatial distribution in the eq. latitude- $\theta$ space of the APs, defined by the mixing ratios of $\mathrm{N}_{2} \mathrm{O}$ and $p \mathrm{O}_{3}$ inside the square in Fig. 9a3, i.e. with $\mathrm{N}_{2} \mathrm{O}$ and $\mathrm{pO}_{3}$ values from 80 to 130 and from 2.7 to 3.5 ppmv, respectively, calculated from the CLaMS run without mixing. (a) 23 December 2008; (b) 23 January 2009 and (c) 23 February 2009. Colours indicate different ranges of $p \mathrm{O}_{3}$ values and are defined in the box. The PDFs along the eq. latitude and potential temperature axes are shown as red lines. Thick black lines denote the edge of the polar vortex.

To shed more light on the ongoing processes, in Fig. 10 we plot the eq. latitudes and the potential temperature coordinates of these missing APs at the end of each of the considered time periods (from the CLaMS run without mixing). Furthermore, the APs are coloured by different ranges of $p \mathrm{O}_{3}$ and the PDFs of their eq. latitudes and $\theta$ coordinates describe their mean horizontal and vertical position during the course of the winter.

Figure 10 shows that after the major SSW onset, most of the APs which were originally located above $450 \mathrm{~K}$, have been transported downwards below $450 \mathrm{~K}$. Therefore, the downward cross-isentropic transport within the vortex (diabatic descent) with subsequent export of the APs out of the considered potential temperature range $450-700 \mathrm{~K}$ is the main reason for the missing correlation inside the square of Fig. 9c3. Moreover, most of the APs were confined inside the polar vortex before the major SSW, while after the major SSW these APs were spread almost uniformly between 40 and $90^{\circ} \mathrm{N}$ eq. latitude (Fig. 10c) due to chaotic advection with pronounced streamers and filaments after a complete breakup of the two vortices over eastern North America and the Atlantic (see $\mathrm{N}_{2} \mathrm{O}$ distribution at $475 \mathrm{~K}$ in Fig. 4).

In the CLaMS run with mixing, the situation is stable as long as the well-defined vortex edge constitutes an effective mixing barrier (Fig. 9, column a). Later, during the major SSW, descent and chaotic advection have the same effect as in the idealized CLaMS simulation without mixing, i.e. part of the APs carrying the signature of the polar correlation are again eventually exported from the considered $\theta$-range as they descend below $450 \mathrm{~K}$.

However, increased mixing between these descending polar APs with the APs outside the vortex have two additional effects: (i) the signature of the polar correlation is spread to mid-latitude APs that do not descend beyond the considered $\theta$-range, such that the signature remains visible (like vortex fragment D in Fig. 8b1/c1), and (ii) the mixing with midlatitude (and even tropical) APs causes the polar correlation branch to become less compact and shift toward the midlatitude correlation branch along the plotted isentropes (like air masses $\mathrm{C}$ and $\mathrm{E}$ in Fig. 8b1/c1). These effects can be well discerned by comparing the vortex branch of the correlation for the mixed case (Fig. 9b2/c2) with the non-mixed case (Fig. 9b3/c3), also denoted as dashed black curves in Fig. $9 \mathrm{~b} 2 / \mathrm{c} 2$.

After the breakup of the two vortices over eastern North America and Atlantic in mid February, spreading of the polar APs across the hemisphere along with intense mixing with mostly mid-latitude and some tropical APs leads to an almost complete loss of the polar correlation branch (Fig. 9c2), which remains preserved only in a few unmixed vortex remnants (like fragments A, B and D in Fig. 8c1). As explained by Plumb (2007), the fast and nearly hemisphere-wide isentropic mixing (as promoted by the major SSW) leads to a single compact extratropical correlation.

Note that the weak polar correlation which is present in CLaMS (see Fig. 9c2) is not resolved in the MLS observations. A potential explanation is the limited spatial resolution of the MLS instrument with vertical resolution of 4-6 km for $\mathrm{N}_{2} \mathrm{O}$ and $2.5-3 \mathrm{~km}$ for $\mathrm{O}_{3}$, respectively, and horizontal resolution of $200 \mathrm{~km}$ for both species. This means that physical structures below these spatial scales are smoothed out by the MLS instrument (an effect sometimes called optical mixing, see Appendix).

\subsection{Impact of chemistry}

In general, Arctic $\mathrm{O}_{3}$ loss triggered by activated chlorine mainly occurs in late winter and spring within a sufficiently cold polar vortex. The chlorine-induced ozone-loss also requires sunlight exposure (see e.g. Solomon, 1999). The $\mathrm{NO}_{x}$ induced $\mathrm{O}_{3}$ chemistry roughly follows the halogen chem- 


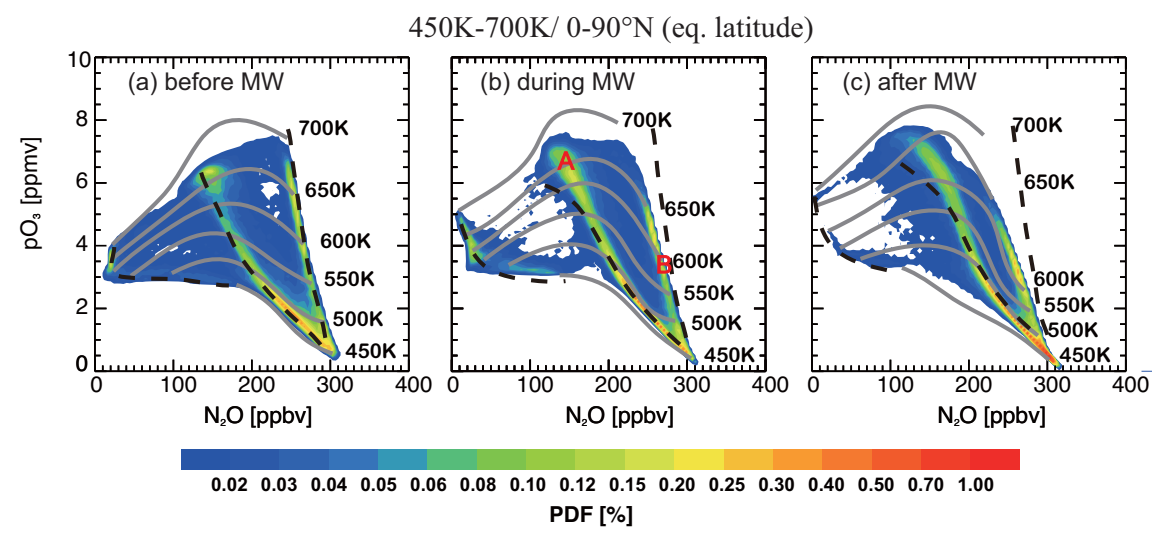

Figure 11. Impact of $\mathrm{O}_{3}$-chemistry on the temporal evolution of the $\mathrm{N}_{2} \mathrm{O}-\mathrm{O}_{3}$ correlations. The PDFs are calculated from the $\mathrm{N}_{2} \mathrm{O}-p \mathrm{O}_{3}$ correlations of APs with eq. latitudes $0-90^{\circ} \mathrm{N}$ and potential temperatures $450-700 \mathrm{~K}$. The considered time periods are the same as in Fig. 9 . The dashed black curves fit the maxima of the $\mathrm{N}_{2} \mathrm{O}-\mathrm{O}_{3}$ correlations (PDFs) derived from a CLaMS run with a full stratospheric ozone chemistry. The correlation for passive ozone $\left(p \mathrm{O}_{3}\right)$ marked as $\mathrm{A}\left(\mathrm{N}_{2} \mathrm{O}\right.$ near 140 ppbv and $p \mathrm{O}_{3}$ near 7400 ppbv $)$ and the correlation marked as $\mathrm{B}\left(\mathrm{N}_{2} \mathrm{O}\right.$ near $140 \mathrm{ppbv}$ and $\mathrm{pO}_{3}$ near $\left.7400 \mathrm{ppbv}\right)$ show clear differences from the dashed curves showing simulation with full chemistry. The two groups of APs marked by those correlation features have been investigated in more detail of their ozone chemistry (see text).

istry after the vortex breakup with highest values occurring in the middle and lower stratosphere (see e.g. Solomon, 1999; WMO, 2014). To quantify the chemical effect on the $\mathrm{N}_{2} \mathrm{O}-\mathrm{O}_{3}$ correlation, Fig. 11 shows the $p \mathrm{O}_{3}-\mathrm{N}_{2} \mathrm{O}$ correlation within $0-90^{\circ} \mathrm{N}$ and $450-700 \mathrm{~K}$ range, overlaid with the correlations from the full chemistry run (dashed curves).

In the early winter, we found a small but significant amount of ozone loss in the lower stratosphere (cf. dashed curve and PDFs between 450 and $550 \mathrm{~K}$ in Fig. 11b), which is consistent with the results of Manney et al. (2015). After the onset of the warming event, only few polar stratospheric clouds (PSCs) were formed and, consequently, the subsequent, chlorine-induced ozone-loss within the polar vortex was very limited (Kuttippurath and Nikulin, 2012; Manney et al., 2015). This can also be inferred from the CLaMSbased correlation with $p \mathrm{O}_{3}$ (PDFs in Fig. 11c) that is very close to the correlation based on full-chemistry $\mathrm{O}_{3}$ (dashed curve in Fig. 11c). Besides the chlorine-catalyzed ozone loss, the remaining $\mathrm{O}_{3}$ chemistry is of importance in our interpretation of the $\mathrm{N}_{2} \mathrm{O}-\mathrm{O}_{3}$ correlations, especially when the temperature rises after the major SSW and thus the chemical reactions are accelerated.

Two regions (marked in Fig. 11 as A and B) of this correlation plot have been investigated in more detail regarding the chemical change of ozone. Region (A) has $\mathrm{N}_{2} \mathrm{O}$ mixing ratios near $140 \mathrm{ppbv}$ and passive ozone near $7.4 \mathrm{ppmv}$ on 23 January, corresponding to a most probable location of $35^{\circ} \mathrm{N}$ and $650 \mathrm{~K}$ (using a similar method as discussed in Fig. 10). It is evident that here the chemistry causes ozone depletion. From the locations of 120 air parcels in this area, back trajectories were calculated for 1 month along which the chemistry, which was calculated using the CLaMS chemistry module, and additional output to analyse and quantify the contribution of the individual ozone depletion cycles (as defined by Crutzen et al., 1995) to the ozone loss term. The average ozone production over this month through oxygen photolysis was $0.85 \mathrm{ppmv}$ which was outweighed by ozone loss of 1.45 ppmv, of which about half could be attributed to $\mathrm{NO}_{x}$ catalyzed ozone loss cycles and the remaining half equally distributed to $\mathrm{HO}_{x}, \mathrm{ClO}_{x}$ and $\mathrm{O}_{x}$ cycles.

In contrast, region (B) with $\mathrm{N}_{2} \mathrm{O}$ mixing ratios of $260 \mathrm{ppbv}$ and passive ozone mixing ratios of 3.8 ppmv corresponds to a most probable location of $11^{\circ} \mathrm{N}$ and $575 \mathrm{~K}$. Here, the chemistry causes an ozone increase. A similar chemistry simulation along 132 1-month back trajectories showed an ozone production through oxygen photolysis of $800 \mathrm{ppbv}$ and net ozone depletion by 260 ppbv. Therefore ozone production dominates in this part of the tropics. Since gas-phase chemical reactions are temperature-dependent, we investigated whether the temperature anomaly (see Fig. 1b) had a significant effect on ozone. An identical run along the 132 trajectories, however, with temperatures set $3 \mathrm{~K}$ higher, increased the ozone loss by $0.03 \mathrm{ppmv}$. The ozone production is not temperature-dependent. A change in the ozone loss rate of $1 \mathrm{ppbv}$ per day is negligible compared to the changes caused by dynamics that are discussed here. Complementary to our discussion above, we find that in polar latitudes, the differences between correlations with or without chemistry are negligible, indicating minor importance of the chlorineinduced ozone-loss during the 2008/09 winter.

\section{Conclusions}

A remarkable major SSW in January 2009 led to strongly disturbed stratospheric dynamics which manifested in both accelerated polar descent and tropical upwelling. During the following 2 weeks up to the end of January, this transient 
signal of cross-isentropic transport propagated down from around 1 to $100 \mathrm{hPa}$. The radiative relaxation of this anomaly in diabatic heating was relatively fast $(\sim 10$ days $)$ in the upper stratosphere, but took more than a month in the lower stratosphere, which resulted in accelerated polar descent and accelerated tropical upwelling through late March (Fig. 2).

Associated with the disturbed dynamical background during the major SSW, strong variability of $\mathrm{N}_{2} \mathrm{O}$ and $\mathrm{O}_{3}$ was observed by the MLS instrument. We used CLaMS to simulate transport, mixing and chemistry to interpret the observed change of stratospheric composition. By comparison with MLS observations of $\mathrm{N}_{2} \mathrm{O}-\mathrm{O}_{3}$ correlations, we showed how the polar vortex edge weakened and how the subtropical mixing barrier was affected by poleward transport followed by mixing in mid latitudes during and after the major SSW.

As an important but uncertain piece of atmospheric modelling, the mixing process could be explicitly and reasonably described in CLaMS simulations. The distribution of simulated mixing intensity showed that mixing across the vortex edge and also across the subtropical barrier (above $700 \mathrm{~K}$ ) was enhanced after the onset of the major SSW, associated with wave forcing, quantified in terms of the EP flux divergence.

The observation- and model-based $\mathrm{O}_{3}-\mathrm{N}_{2} \mathrm{O}$ correlations have been shown to be a useful diagnostic to separate dynamical and chemical effects. Model results show that isentropic mixing is a key process to understand the drastic change of stratospheric composition triggered by the major SSW: the decay of the polar $\mathrm{O}_{3}-\mathrm{N}_{2} \mathrm{O}$ correlation and the strengthening of the mid-latitude correlation. One month after the major SSW, almost half of the polar vortex correlation dissolved due to isentropic mixing, whereas the other part constituted the germ for the formulation of a new and relatively weak vortex. Halogen-induced ozone loss within the polar vortex was negligible in the late winter of 2008/09 and the dominant ozone chemistry during and after the major SSW was the extra-tropical ozone loss due to $\mathrm{NO}_{x}$ catalytic cycles mainly at $600-800 \mathrm{~K}$ and ozone production in the tropics.

However, there is also a limitation of the applicability of the MLS satellite data with a vertical resolution of a few kilometres. As shown in the Appendix, due to this limited spatial resolution, physical structures below these spatial scales and resolved by the model are smoothed out by the satellite's averaging kernel (an effect sometimes called optical mixing). Thus, although MLS satellite data offer a very good coverage, their poor vertical resolution does not allow us to narrow the possible range of the mixing parameters in CLaMS (i.e. of the critical Lyapunov exponent).

Finally, we can speculate that for a winter with significant, chlorine-induced ozone loss, followed by a strong major SSW and/or a final warming, the mid-latitude air can be influenced by processed, ozone-depleted air. Conversely, mid-latitude air (also $\mathrm{O}_{3}$-rich air compared to polar vortex air in mid stratosphere) can be effectively transported into the high latitudes. 


\section{Appendix A}

As discussed in Sect. 3.2, the MLS averaging kernels were applied for both the $\mathrm{N}_{2} \mathrm{O}$ and $\mathrm{O}_{3}$ CLaMS output before comparing these distributions with the satellite-based observations. Given a "true" atmospheric profile $x_{i}$ on $n$ pressure levels $i=1, \ldots, n$, the averaging kernel can be understood as a smoothing procedure that determines mixing ratios at each level $i$ by a weighted integration over all other levels with a strongest contribution of levels directly above or below the considered level $i$. The averaging kernel is a matrix $A_{i j}$ with most significant terms around the diagonal and with all rows $i$ fulfilling the normalization condition $\sum_{j=1, \ldots, n} A_{i j}=1$. Thus, applying averaging kernels to model data with a high spatial resolution like CLaMS means smoothing or removing small-scale structures from the model.

In Fig. $\mathrm{A} 1$, the PDFs of the $\mathrm{N}_{2} \mathrm{O}-\mathrm{O}_{3}$ correlations are shown for 15 February 2009 as observed by the MLS instrument (top) and as derived from CLaMS simulations with and without smoothing by the averaging kernel (bottom). In contrast to MLS, original CLaMS output shows the polar correlation, which disappears if the averaging kernel is applied to CLaMS output. This polar correlation can be attributed to some remnants of the polar vortex which are resolved by CLaMS. Within the model, the lifetime of the polar correlation is about 3 weeks longer compared to the last time this correlation was detected by the MLS instrument.

Thus, two questions arise: are these small-scale structures resolved with CLaMS realistic and is it the $\mathrm{N}_{2} \mathrm{O}$ or rather the $\mathrm{O}_{3}$-related coarse sampling of the MLS instrument that smoothes out the polar correlation of $\mathrm{N}_{2} \mathrm{O}-\mathrm{O}_{3}$ ? To get an impression of how the averaging kernel smoothes out the modelled small-scale filaments and tracer gradients, Fig. A2 shows the spatial distribution of $\mathrm{N}_{2} \mathrm{O}$ vortex remnants on 20 February 2009 before and after applying the MLS averaging kernel procedure (left and right column, respectively). Here, $\mathrm{N}_{2} \mathrm{O}$ distributions at two isentropic levels, $550 \mathrm{~K}$ (top row) and $650 \mathrm{~K}$ (bottom row) are shown, with black lines denoting the strongly disturbed vortex edge.

$\mathrm{N}_{2} \mathrm{O}$ and $\mathrm{O}_{3}$ profiles from the Atmospheric Chemistry Experiment (ACE) are also used. An ACE profile crossed the potential surfaces $\theta=550$ and $660 \mathrm{~K}$ on this day (red circles as the profile positions at noon on each isentrope). The nearest CLaMS APs are selected according to the same procedure as for the MLS data (see Sect. 3.2). Thus, the horizontal spatial distances of ACE profiles and corresponding CLaMS profiles are less than $50 \mathrm{~km}\left(1.5^{\circ}\right)$. The vertical resolution of ACE profiles is about 3-4 km (Bernath et al., 2005; Boone et al., 2005).

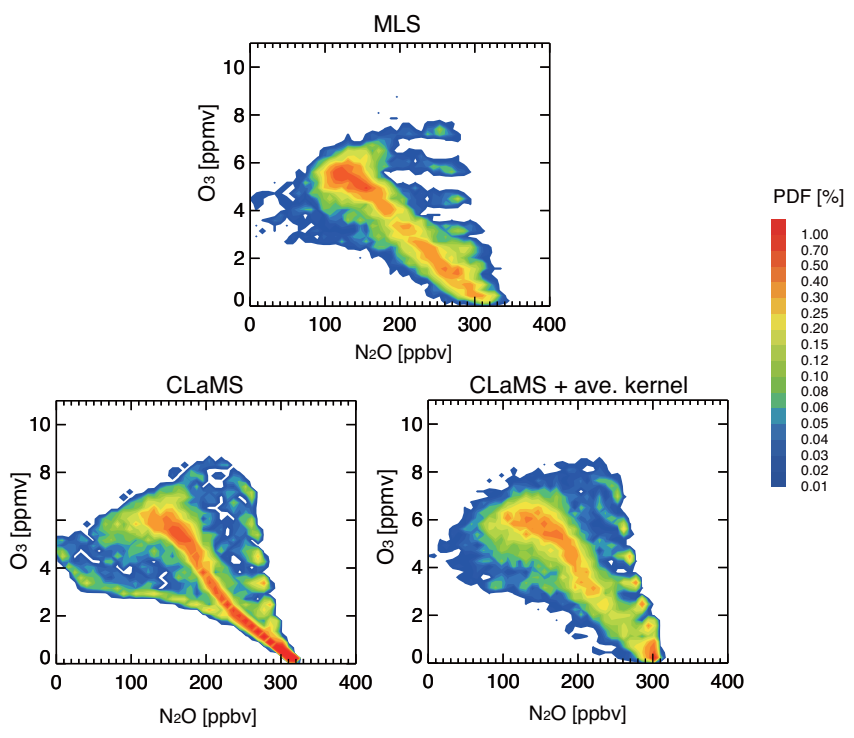

Figure A1. PDFs of $\mathrm{N}_{2} \mathrm{O}-\mathrm{O}_{3}$ correlations on 15 February 2009 from MLS observations (top); from the reference CLaMS simulation without applying the averaging kernel (bottom left) and after applying the averaging kernel (bottom right).

It can be seen that the vertical variability of the untreated CLaMS simulation of $\mathrm{N}_{2} \mathrm{O}$ is confirmed by the corresponding ACE profile (top panel in Fig. A3). On the other hand, this variability is removed from the CLaMS simulation if the MLS averaging kernel is applied and, consequently, the comparison with the ACE observations becomes worse. However, the smoothing does not significantly change the $\mathrm{O}_{3}$ profiles (bottom panel in Fig. A3). This is mainly because the vertical variability of $\mathrm{O}_{3}$ is much smaller if compared with the $\mathrm{N}_{2} \mathrm{O}$ profile and not because of a higher vertical resolution of the MLS-based $\mathrm{O}_{3}$ observations (i.e. $2.5-3 \mathrm{~km}$ for $\mathrm{O}_{3}$ versus 5-6 $\mathrm{km}$ for $\mathrm{N}_{2} \mathrm{O}$ ).

This can also be inferred from the comparison of the horizontal and vertical gradients of both tracers. Within the vertical range between $\theta=400$ and $800 \mathrm{~K}$, the horizontal variability of $\mathrm{N}_{2} \mathrm{O}$ across the vortex edge $(\sim 100 \mathrm{ppbv})$ is comparable with the vertical variability $(\sim 150 \mathrm{ppbv})$, whereas the $\mathrm{O}_{3}$ gradient across the polar vortex edge (around 1$2 \mathrm{ppmv}$ ) is much smaller than its vertical gradient in the stratosphere $(\sim 5 \mathrm{ppmv})$. Therefore, the filaments or vortex remnants which are not completely mixed, and which are mainly formed by the horizontal transport, contribute to a more pronounced vertical variability of $\mathrm{N}_{2} \mathrm{O}$ than of the $\mathrm{O}_{3}$ profiles. 

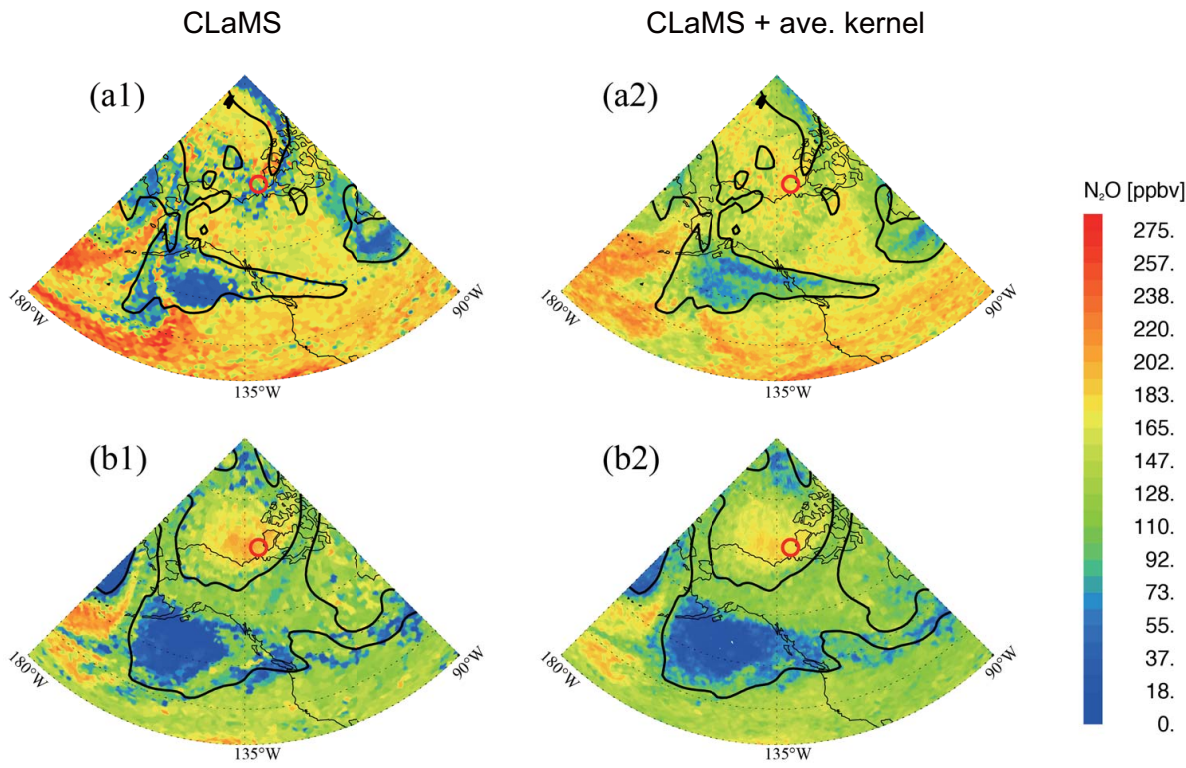

Figure A2. Spatial distribution of $\mathrm{N}_{2} \mathrm{O}$ on 20 February 2009, i.e. almost 1 month after the major SSW at $\theta=550 \mathrm{~K}$ (top row) and $650 \mathrm{~K}$ (bottom row). Here the results of the reference run without and with the averaging kernel are shown in the left and right column, respectively. The black line denotes the vortex edge, the red circles are the noon-footprints calculated by the observed ACE profile through back and forward trajectory.
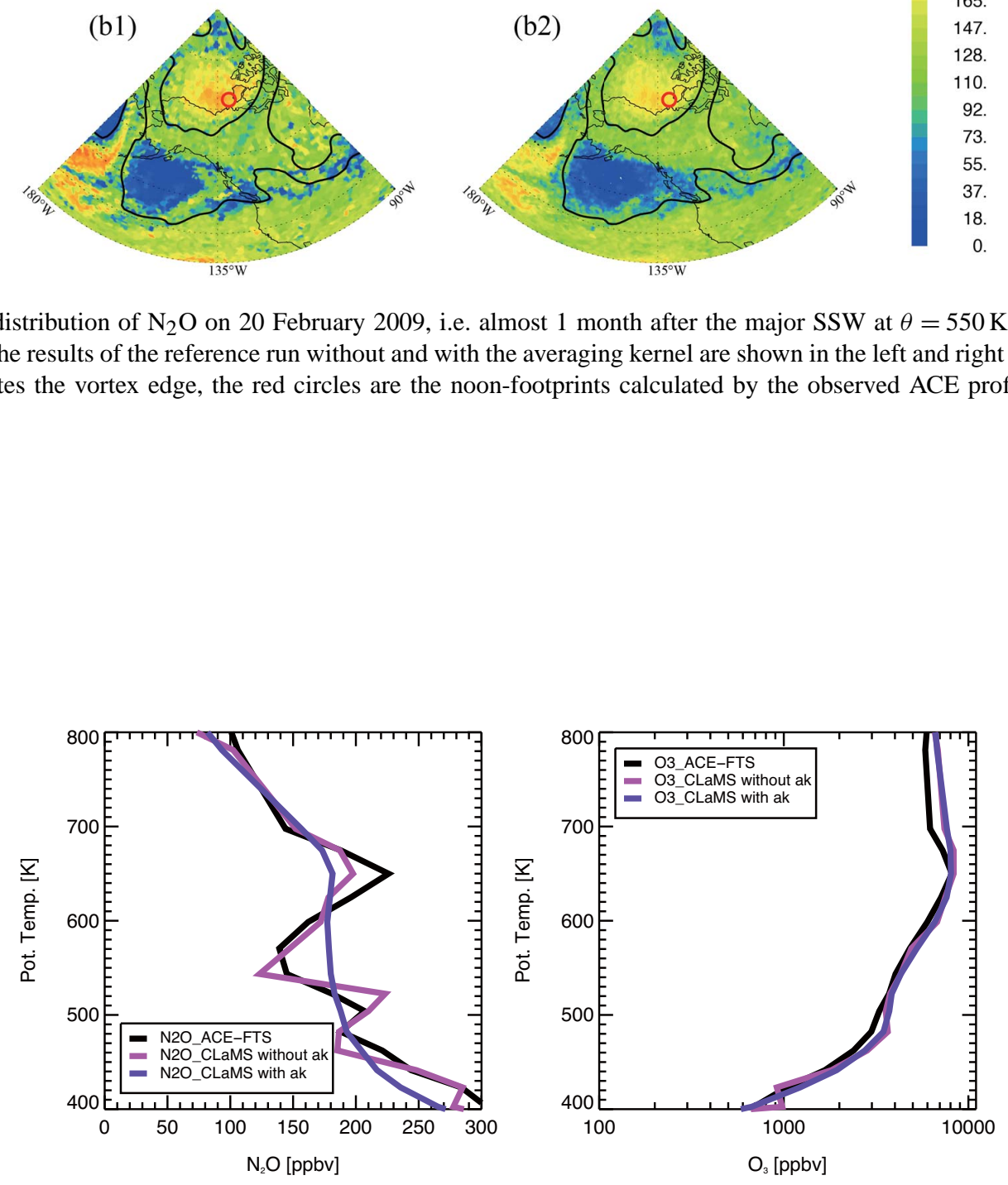

Figure A3. $\mathrm{N}_{2} \mathrm{O}$ (top) and $\mathrm{O}_{3}$ (bottom) profiles of ACE observations (black) on 20 February located at $73.05^{\circ} \mathrm{N}, 137.11^{\circ} \mathrm{W}$ at $30 \mathrm{~km}$, and of corresponding CLaMS simulation before (blue) and after (purple) applying the MLS averaging kernel. 
Acknowledgements. We thank ECMWF for providing reanalysis data and the MLS team for providing the $\mathrm{N}_{2} \mathrm{O}$ and $\mathrm{O}_{3}$ data. Excellent programming support was provided by N. Thomas. We thank the Atmospheric Chemistry Experiment (ACE) team, a Canadian-led mission mainly supported by the Canadian Space Agency and the Natural Sciences and Engineering Research Council of Canada, for providing the $\mathrm{N}_{2} \mathrm{O}$ and $\mathrm{O}_{3}$ data. We thank Eric Ray, Gloria Manney and an anonymous reviewer for their very thoughtful and helpful reviews.

The article processing charges for this open-access publication were covered by a Research

Centre of the Helmholtz Association.

Edited by: M. Dameris

\section{References}

Andrews, D. G., Holton, J. R., and Leovy, C. B.: Middle Atmosphere Dynamics, Academic Press, San Diego, USA, 1987.

Ayarzagüena, B., Langematz, U., and Serrano, E.: Tropospheric forcing of the stratosphere: A comparative study of the two different major stratospheric warmings in 2009 and 2010, J. Geophys. Res.-Atmos., 1984-2012, 116, D18114, doi:10.1029/2010JD015023, 2011.

Bernath, P., McElroy, C., Abrams, M., Boone, C., Butler, M., CamyPeyret, C., Carleer, M., Clerbaux, C., Coheur, P., Colin, R., DeCola, P., Bernath, P., McElroy, C., Abrams, M., Boone, C., Butler, M., Camy-Peyret, C., Carleer, M., Clerbaux, C., Coheur, P., Colin, R., DeCola, P., DeMaziere, M., Drummond, J., Dufour, D., Evans, W., Fast, H., Fussen, D., Gilbert, K., Jennings, D., Llewellyn, E., Lowe, R., Mahieu, E., McConnell, J., McHugh, M., McLeod, S., Michaud, R., Midwinter, C., Nassar, R., Nichitiu, F., Nowlan, C., Rinsland, C., Rochon, Y., Rowlands, N., Semeniuk, K., Simon, P., Skelton, R., Sloan, J., Soucy, M., Strong, K., Tremblay, P., Turnbull, D., Walker, K., Walkty, I., Wardle, D., Wehrle, V., Zander, R., and Zou, J.: Atmospheric Chemistry Experiment (ACE): Mission overview, Geophys. Res. Lett., 32, L15S01, doi:10.1029/2005GL022386, 2005.

Boone, C. D., Nassar, R., Walker, K. A., Rochon, Y., McLeod, S. D., Rinsland, C. P., and Bernath, P. F.: Retrievals for the atmospheric chemistry experiment Fourier-transform spectrometer, Appl. Optics, 44, 7218-7231, 2005.

Butler, A. H., Seidel, D. J., Hardiman, S. C., Butchart, N., Birner, T., and Match, A.: Defining sudden stratospheric warmings, B. Am. Meteorol. Soc., doi:0.1175/BAMS-D-13-00173.1, online first, 2015.

Charlton, A. J. and Polvani, L. M.: A new look at stratospheric sudden warmings. Part I: Climatology and modeling benchmarks, J. Climate, 20, 449-469, 2007.

Christiansen, B.: Downward propagation of zonal mean zonal wind anomalies from the stratosphere to the troposphere: Model and reanalysis, J. Geophys. Res.-Atmos., 106, 27307-27322, 2001.

Crutzen, P. J., Grooß, J.-U., Brühl, C., Müller, R., and Russell III, J. M.: A Reevaluation of the ozone budget with HALOE UARS data: No evidence for the ozone deficit, Science, 268, 705-708, 1995.
Dee, D. P., Uppala, S. M., Simmons, A. J., Berrisford, P., Poli, P., Kobayashi, S., Andrae, U., Balmaseda, M. A., Balsamo, G., Bauer, P., Bechtold, P., Beljaars, A. C. M., van de Berg, L., Bidlot, J., Bormann, N., Delsol, C., Dragani, R., Fuentes, M., Geer, A. J., Haimberger, L., Healy, S. B., Hersbach, H., Holm, E. V., Isaksen, L., Kallberg, P., Kohler, M., Matricardi, M., McNally, A. P., Monge-Sanz, B. M., Morcrette, J. J., Park, B. K., Peubey, C., de Rosnay, P., Tavolato, C., Thepaut, J. N., and Vitart, F.: The ERA-Interim reanalysis: configuration and performance of the data assimilation system, Q. J. Roy. Meteorol. Soc., 137, 553597, doi:10.1002/qj.828, 2011.

Dickinson, R. E.: On the exact and approximate linear theory of vertically propagating planetary Rossby waves forced at a spherical lower boundary, Mon. Weather Rev., 96, 405-415, 1968.

Edouard, S., Legras, B., Lefèvre, F., and Eymard, R.: The effect of small-scale inhomogeneities on ozone depletion in the Arctic, Nature, 384, 444-447, 1996.

Eliassen, A.: Slow thermally or frictionally controlled meridional circulation in a circular vortex, Astrophysica Norvegica, 5, 19 pp., 1951.

Fairlie, T. D., Pierce, R. B., Grose, W. L., Lingenfelser, G., Loewenstein, M., and Podolske, J. R.: Lagrangian forecasting during ASHOE/MAESA: Analysis of predictive skill for analyzed and reverse-domain-filled potential vorticity, J. Geophys. Res., 102, 13169-13182, 1997.

Gómez-Escolar, M., Calvo, N., Barriopedro, D., and Fueglistaler, S.: Tropical Response to Stratospheric Sudden Warmings and its modulation by the QBO, J. Geophys. Res.-Atmos., 119, 73827395, doi:10.1002/2013JD020560, 2014.

Grooß, J.-U., Engel, I., Borrmann, S., Frey, W., Günther, G., Hoyle, C. R., Kivi, R., Luo, B. P., Molleker, S., Peter, T., Pitts, M. C., Schlager, H., Stiller, G., Vömel, H., Walker, K. A., and Müller, R.: Nitric acid trihydrate nucleation and denitrification in the Arctic stratosphere, Atmos. Chem. Phys., 14, 1055-1073, doi:10.5194/acp-14-1055-2014, 2014.

Grooß, J.-U., Günther, G., Müller, R., Konopka, P., Bausch, S., Schlager, H., Voigt, C., Volk, C. M., and Toon, G. C.: Simulation of denitrification and ozone loss for the Arctic winter 2002/2003, Atmos. Chem. Phys., 5, 1437-1448, doi:10.5194/acp-5-14372005, 2005a.

Grooß, J.-U., Konopka, P., and Müller, R.: Ozone chemistry during the 2002 Antarctic vortex split, J. Atmos. Sci., 62, 860-870, $2005 b$.

Harada, Y., Goto, A., Hasegawa, H., Fujikawa, N., Naoe, H., and Hirooka, T.: A major stratospheric sudden warming event in January 2009, J. Atmos. Sci., 67, 2052-2069, 2010.

Haynes, P. and Shuckburgh, E.: Effective diffusivity as a diagnostic of atmospheric transport, 1, Stratosphere, J. Geophys. Res., 105, 22777-22794, 2000.

Hegglin, M. I. and Shepherd, T. G.: $\mathrm{O}_{3}-\mathrm{N}_{2} \mathrm{O}$ correlations from the Atmospheric Chemistry Experiment: Revisiting a diagnostic of transport and chemistry in the stratosphere, J. Geophys. Res., 112, D19301, doi:10.1029/2006JD008281, 2007.

Hitchcock, P. and Shepherd, T. G.: Zonal-mean dynamics of extended recoveries from stratospheric sudden warmings, J. Atmos. Sci., 70, 688-707, 2013.

Holton, J. R., Haynes, P., McIntyre, M. E., Douglass, A. R., Rood, R. B., and Pfister, L.: Stratosphere-troposphere exchange, Rev. Geophys., 33, 403-439, 1995. 
Hoppe, C. M., Hoffmann, L., Konopka, P., Grooß, J.-U., Ploeger, F., Günther, G., Jöckel, P., and Müller, R.: The implementation of the CLaMS Lagrangian transport core into the chemistry climate model EMAC 2.40.1: application on age of air and transport of long-lived trace species, Geosci. Model Dev., 7, 2639-2651, doi:10.5194/gmd-7-2639-2014, 2014.

Khosrawi, F., Grooß, J.-U., Müller, R., Konopka, P., Kouker, W., Ruhnke, R., Reddmann, T., and Riese, M.: Intercomparison between Lagrangian and Eulerian simulations of the development of mid-latitude streamers as observed by CRISTA, Atmos. Chem. Phys., 5, 85-95, doi:10.5194/acp-5-85-2005, 2005.

Konopka, P., Grooß, J.-U., Bausch, S., Müller, R., McKenna, D. S., Morgenstern, O., and Orsolini, Y.: Dynamics and chemistry of vortex remnants in late Arctic spring 1997 and 2000: Simulations with the Chemical Lagrangian Model of the Stratosphere (CLaMS), Atmos. Chem. Phys., 3, 839-849, doi:10.5194/acp-3839-2003, 2003.

Konopka, P., Steinhorst, H.-M., Grooß, J.-U., Günther, G., Müller, R., Elkins, J. W., Jost, H.-J., Richard, E., Schmidt, U., Toon, G., and McKenna, D. S.: Mixing and Ozone Loss in the 1999-2000 Arctic Vortex: Simulations with the 3-dimensional Chemical Lagrangian Model of the Stratosphere (CLaMS), J. Geophys. Res., 109, D02315, doi:10.1029/2003JD003792, 2004.

Konopka, P., Grooß, J.-U., Hoppel, K. W., Steinhorst, H.-M., and Müller, R.: Mixing and chemical ozone loss during and after the Antarctic polar vortex major warming in September 2002, J. Atmos. Sci., 62, 848-859, 2005.

Konopka, P., Günther, G., Müller, R., dos Santos, F. H. S., Schiller, C., Ravegnani, F., Ulanovsky, A., Schlager, H., Volk, C. M., Viciani, S., Pan, L. L., McKenna, D.-S., and Riese, M.: Contribution of mixing to upward transport across the tropical tropopause layer (TTL), Atmos. Chem. Phys., 7, 3285-3308, doi:10.5194/acp-7-3285-2007, 2007.

Konopka, P., Grooß, J.-U., Günther, G., Ploeger, F., Pommrich, R., Müller, R., and Livesey, N.: Annual cycle of ozone at and above the tropical tropopause: observations versus simulations with the Chemical Lagrangian Model of the Stratosphere (CLaMS), Atmos. Chem. Phys., 10, 121-132, doi:10.5194/acp-10-121-2010, 2010.

Kuttippurath, J. and Nikulin, G.: A comparative study of the major sudden stratospheric warmings in the Arctic winters 2003/2004-2009/2010, Atmos. Chem. Phys., 12, 8115-8129, doi:10.5194/acp-12-8115-2012, 2012.

Labitzke, K. and Kunze, M.: On the remarkable Arctic winter in 2008/2009, J. Geophys. Res.-Atmos., 114, D00I02, doi:10.1029/2009JD012273, 2009.

Lahoz, W. A., Errera, Q., Viscardy, S., and Manney, G. L.: The 2009 stratospheric major warming described from synergistic use of BASCOE water vapour analyses and MLS observations, Atmos. Chem. Phys., 11, 4689-4703, doi:10.5194/acp-11-46892011, 2011.

Lemmen, C., Müller, R., Konopka, P., and Dameris, M.: Critique of the tracer-tracer correlation technique and its potential to analyse polar ozone loss in chemistry-climate models, J. Geophys. Res., 111, D18307, doi:10.1029/2006JD007298, 2006.

Livesey, N. J., Read, W. G., Froidevaux, L., Lambert, A., Manney, G. L., Pumphrey, H. C., Santee, M. L., Schwartz, M. J., Wang, S., Cofield, R. E., Cuddy, D. T., Fuller, R. A., Jarnot, R. F., Jiang, J. H., Knosp, B. W., Stek, P. C., Wagner, P. A., and Wu,
D. L.: Version 3.3 and 3.4 Level 2 data quality and description document, JPL D-33509, https://mls.jpl.nasa.gov/data/v3_data_ quality_document.pdf, 2013.

Mahowald, N. M., Plumb, R. A., Rasch, P. J., del Corral, J., and Sassi, F.: Stratospheric transport in a three-dimensional isentropic coordinate model, J. Geophys. Res., 107, 4254, doi:10.1029/2001JD001313, 2002.

Manney, G. L., Bird, J. C., Donovan, D. P., Duck, T. J., Whiteway, J. A., Pal, S. R., and Carswell, A. I.: Modeling ozone laminae in ground-based Arctic wintertime observations using trajectory calculations and satellite data, J. Geophys. Res., 103, 5797-5814, 1998.

Manney, G. L., Krüger, K., Sabutis, J. L., Amina Sena, S., and Pawson, S.: The remarkable 2003-2004 winter and other recent warm winters in the Arctic stratosphere in the late 1990s, J. Geophys. Res., 110, D04107, doi:10.1029/2004JD005367, 2005.

Manney, G. L., Krüger, K., Pawson, S., Minschwaner, K., Schwartz, M. J., Daffer, W. H., Livesey, N. J., Mlynczak, M. G., Remsberg, E. E., Russell, J. M., and Water, J. W.: The evolution of the stratopause during the 2006 major warming: Satellite data and assimilated meteorological analyses, J. Geophys. Res.-Atmos., 113, D11115, doi:10.1029/2007JD009097, 2008.

Manney, G. L., Harwood, R. S., MacKenzie, I. A., Minschwaner, K., Allen, D. R., Santee, M. L., Walker, K. A., Hegglin, M. I., Lambert, A., Pumphrey, H. C., Bernath, P. F., Boone, C. D., Schwartz, M. J., Livesey, N. J., Daffer, W. H., and Fuller, R. A.: Satellite observations and modeling of transport in the upper troposphere through the lower mesosphere during the 2006 major stratospheric sudden warming, Atmos. Chem. Phys., 9, 47754795, doi:10.5194/acp-9-4775-2009, 2009a.

Manney, G. L., Schwartz, M. J., Krüger, K., Santee, M. L., Pawson, S., Lee, J. N., Daffer, W. H., Fuller, R. A., and Livesey, N. J.: Aura Microwave Limb Sounder observations of dynamics and transport during the record-breaking 2009 Arctic stratospheric major warming, Geophys. Res. Lett., 36, L12815, doi:10.1029/2009GL038586, 2009b.

Manney, G. L., Lawrence, Z. D., Santee, M. L., Livesey, N. J., Lambert, A., and Pitts, M. C.: Polar processing in a split vortex: Arctic ozone loss in early winter 2012/2013, Atmos. Chem. Phys., 15, 5381-5403, doi:10.5194/acp-15-5381-2015, 2015.

Matsuno, T.: A dynamical model of the stratospheric sudden warming, J. Atmos. Sci., 28, 1479-1494, 1971.

McIntyre, M. E. and Palmer, T. N.: Breaking planetary waves in the stratosphere, Nature, 305, 593-600, 1983.

McKenna, D. S., Grooß, J.-U., Günther, G., Konopka, P., Müller, R., Carver, G., and Sasano, Y.: A new Chemical Lagrangian Model of the Stratosphere (CLaMS): 2. Formulation of chemistry scheme and initialization, J. Geophys. Res., 107, 4256, doi:10.1029/2000JD000113, 2002a.

McKenna, D. S., Konopka, P., Grooß, J.-U., Günther, G., Müller, R., Spang, R., Offermann, D., and Orsolini, Y.: A new Chemical Lagrangian Model of the Stratosphere (CLaMS): 1. Formulation of advection and mixing, J. Geophys. Res., 107, 4309, doi:10.1029/2000JD000114, 2002b.

Michelsen, H. A., Manney, G. L., Gunson, M. R., and Zander, R.: Correlations of stratospheric abundances of $\mathrm{NO}_{y}, \mathrm{O}_{3}, \mathrm{~N}_{2} \mathrm{O}$, and $\mathrm{CH}_{4}$ derived from ATMOS measurements, J. Geophys. Res., 103, 28347-28359, 1998. 
Mlynczak, M. G., Mertens, C. J., Garcia, R. R., and Portmann, R. W.: A detailed evaluation of the stratospheric heat budget: 2 . Global radiation balance and diabatic circulations, J. Geophys. Res., 104, 6039-6066, 1999.

Müller, R., Crutzen, P. J., Grooß, J.-U., Brühl, C., Russell III, J. M., and Tuck, A. F.: Chlorine activation and ozone depletion in the Arctic vortex: Observations by the Halogen Occultation Experiment on the Upper Atmosphere Research Satellite, J. Geophys. Res., 101, 12531-12554, 1996.

Müller, R., Schmidt, U., Engel, A., McKenna, D. S., and Proffitt, M. H.: The $\mathrm{O}_{3}-\mathrm{N}_{2} \mathrm{O}$ relationship from balloon-borne observations as a measure of Arctic ozone loss in 1991/92, Q. J. Roy. Meteorol. Soc., 127, 1389-1412, 2001.

Müller, R., Tilmes, S., Konopka, P., Grooß, J.-U., and Jost, H.J.: Impact of mixing and chemical change on ozone-tracer relations in the polar vortex, Atmos. Chem. Phys., 5, 3139-3151, doi:10.5194/acp-5-3139-2005, 2005.

Nash, E. R., Newman, P. A., Rosenfield, J. E., and Schoeberl, M. R.: An objective determination of the polar vortex using Ertel's potential vorticity, J. Geophys. Res., 101, 9471-9478, 1996.

Newman, P. A., Nash, E. R., and Rosenfield, J. E.: What controls the temperature of the Arctic stratosphere during the spring?, J. Geophys. Res., 106, 19999-20010, doi:10.1029/2000JD000061, 2001.

Orsolini, Y. J., Hansen, G., Hoppe, U. P., Manney, G. L., and Fricke, K. H.: Dynamical modelling of wintertime lidar observations in the Arctic, Q. J. Roy. Meteorol. Soc., 123, 785-800, 1997.

Orsolini, Y. J., Urban, J., Murtagh, D. P., Lossow, S., and Limpasuvan, V.: Descent from the polar mesosphere and anomalously high stratopause observed in 8 years of water vapor and temperature satellite observations by the Odin Sub-Millimeter Radiometer, J. Geophys. Res., 115, D12305, doi:10.1029/2009JD013501, 2010.

Ploeger, F., Konopka, P., Günther, G., J.-U-Grooß, and Müller, R.: Impact of the vertical velocity scheme on modeling transport across the tropical tropopause layer, J. Geophys. Res., 115, D03301, doi:10.1029/2009JD012023, 2010.

Ploeger, F., Günther, G., Konopka, P., Fueglistaler, S., Müller, R., Hoppe, C., Kunz, A., Spang, R., Grooß, J.-U., and Riese, M.: Horizontal water vapor transport in the lower stratosphere from subtropics to high latitudes during boreal summer, J. Geophys. Res., 118, 8111-8127, doi:10.1002/jgrd.50636, 2013.

Plumb, R. A.: A "tropical pipe" model of stratospheric transport, J. Geophys. Res., 101, 3957-3972, 1996.

Plumb, R. A.: Tracer interrelationships in the stratosphere, Rev. Geophys., 45, RG4005, doi:10.1029/2005RG000179, 2007.

Plumb, R. A. and Bell, R. C.: A model of the quasi-biennial oscillation on an equatorial beta-plane, Q. J. Roy. Meteorol. Soc., 108, 335-352, 1982.

Polvani, L. M., Waugh, D., and Plumb, R. A.: On the subtropical edge of the stratospheric surf zone, J. Atmos. Sci., 52, 12881309, 1995.

Pommrich, R., Müller, R., Grooß, J.-U., Konopka, P., Ploeger, F., Vogel, B., Tao, M., Hoppe, C. M., Günther, G., Spelten, N., Hoffmann, L., Pumphrey, H.-C., Viciani, S., D’Amato, F., Volk, C. M., Hoor, P., Schlager, H., and Riese, M.: Tropical troposphere to stratosphere transport of carbon monoxide and long-lived trace species in the Chemical Lagrangian Model of the Stratosphere
(CLaMS), Geosci. Model Dev., 7, 2895-2916, doi:10.5194/gmd7-2895-2014, 2014.

Proffitt, M. H., Margitan, J. J., Kelly, K. K., Loewenstein, M., Podolske, J. R., and Chan, K. R.: Ozone loss in the Arctic polar vortex inferred from high altitude aircraft measurements, Nature, 347, 31-36, 1990.

Punge, H. J., Konopka, P., Giorgetta, M. A., and Müller, R.: Effects of the quasi-biennial oscillation on low-latitude transport in the stratosphere derived from trajectory calculations, J. Geophys. Res., 114, D03102, doi:10.1029/2008JD010518, 2009.

Randall, C., Harvey, V. L., Siskind, D., France, J., Bernath, P., Boone, C., and Walker, K.: $\mathrm{NO}_{x}$ descent in the Arctic middle atmosphere in early 2009, Geophys. Res. Lett., 36, L18811, doi:10.1029/2009GL039706, 2009.

Randel, W. J., Garcia, R. R., and Wu, F.: Time-Dependent Upwelling in the Tropical Lower Stratosphere Estimated from the Zonal-Mean Momentum Budget, J. Atmos. Sci., 59, 2141-2152, 2002.

Ray, E. A., Moore, F. L., Elkins, J. W., Hurst, D. F., Romashkin, P. A., Dutton, G. S., and Fahey, D. W.: Descent and mixing in the 1999-2000 northern polar vortex inferred from in situ tracer measurements, J. Geophys. Res., 107, 8285, doi:10.1029/2001JD000961, 2002.

Riese, M., Ploeger, F., Rap, A., Vogel, B., Konopka, P., Dameris, M., and Forster, P. M.: Impact of uncertainties in atmospheric mixing on simulated UTLS composition and related radiative effects, J. Geophys. Res., 117, D16, doi:10.1029/2012JD017751, 2012.

Sankey, D. and Shepherd, T. G.: Correlations of long-lived chemical species in a middle atmosphere general circulation model, J. Geophys. Res., 108, 4494, doi:10.1029/2002JD002799, 2003.

Shuckburgh, E., Norton, W., Iwi, A., and Haynes, P.: Influence of the quasi-biennial oscillation on isentropic transport and mixing in the tropics and subtropics, J. Geophys. Res., 106, 1432714337, 2001.

Sofieva, V. F., Kalakoski, N., Verronen, P. T., Päivärinta, S.-M., Kyrölä, E., Backman, L., and Tamminen, J.: Polar-night $\mathrm{O}_{3}, \mathrm{NO}_{2}$ and $\mathrm{NO}_{3}$ distributions during sudden stratospheric warmings in 2003-2008 as seen by GOMOS/Envisat, Atmos. Chem. Phys., 12, 1051-1066, doi:10.5194/acp-12-1051-2012, 2012.

Solomon, S.: Stratospheric ozone depletion: A review of concepts and history, Rev. Geophys., 37, 275-316, doi:10.1029/1999RG900008, 1999.

Steinhorst, H.-M., Konopka, P., Günther, G., and Müller, R.: How permeable is the edge of the Arctic vortex - Model studies of the winter 1999-2000, J. Geophys. Res., 110, D06105, doi:10.1029/2004JD005268, 2005.

Sutton, R. T., Maclean, H., Swinbank, R., O’Neill, A., and Taylor, F. W.: High-resolution stratospheric tracer fields estimated from satellite observations using Lagrangian trajectory calculations, J. Atmos. Sci., 51, 2995-3005, 1994.

Taguchi, M.: Latitudinal Extension of Cooling and Upwelling Signals Associated with Stratospheric Sudden Warmings, J. Meteorol. Soc. Jpn., 89, 571-580, 2011.

Tilmes, S., Müller, R., Engel, A., Rex, M., and Russell III, J.: Chemical ozone loss in the Arctic and Antarctic stratosphere between 1992 and 2005, Geophys. Res. Lett., 33, L20812, doi:10.1029/2006GL026925, 2006. 
Tuck, A. F.: Depletion of Antarctic ozone, Nature, 321, 729-730, 1986.

Volk, C. M., Elkins, J. W., Fahey, D. W., Salawitch, R. J., Dutton, G. S., Gilligan, J. M., Proffitt, M. H., Loewenstein, M., Podolske, J. R., Minschwaner, K., Margitan, J. J., and Chan, K. R.: Quantifying transport between the tropical and mid-latitude lower stratosphere, Science, 272, 1763-1768, 1996.
WMO: Scientific Assessment of Ozone Depletion: 2014, Global Ozone Research and Monitoring Project-Report No. 56, Geneva, Switzerland, 2014. 